\title{
Group Self-Evaluation Primes for Autonomous Motivation in Collaborative Learning
}

IJsbrand M. Kramer*1, Nathalie Franc ${ }^{2}$, Francois Maricourt ${ }^{3}$, Muriel Cohen ${ }^{4}$, Thomas Fau ${ }^{2}$, Xavier Nogues $^{5}$, Willem van der Velden ${ }^{6} \&$ Rashmi Kusurkar $^{7}$

${ }^{1}$ UF Biologie, IECB \& INSERM U1026 BIOTIS, University of Bordeaux, 2 rue Robert Escarpit, 33607 Pessac Cedex, France

2 Lycée Victor Louis, 2 avenue de Thouars, 33405 Talence Cedex, France

${ }^{3}$ Lycée Pape Clement, 1 Rue Léo Lagrange, 33600 Pessac, France

${ }^{4}$ Lycée Francois Mauriac, 1 Rue Henri Dunant, 33100 Bordeaux, France

${ }^{5}$ UF Biologie, University of Bordeaux, Bordeaux, France

${ }^{6}$ Euroswitch, Pastorielaan, 4197 BH Buurmalsen, Netherlands

${ }^{7}$ Research in Education, Faculty of Medicine \& LEARN! Research Institute for Learning and

Education. Faculty of Psychology and Education, Vrije Universiteit Amsterdam, De Boelelaan 1105, 1081 HV Amsterdam, Netherlands.

*corresponding author: ijsbrandkramer@gmail.com

Short title: group self-evaluation primes for autonomous motivation

Running head: group work motivation 


\begin{abstract}
We look at group work from a self-determination theory perspective and argue that internalized motivation, also known as autonomous motivation, is the best condition for productive collaboration. A perceived sense of autonomy plays an important role herein. In collaborative projects, this autonomy is determined by: 1) the characteristics of the project, such as choices given and the relevance of the task, and;2) the openness and acceptance of the group. Group dysfunction, or the fear of it, impedes autonomy, even if the task context is fully autonomy supportive. Means of uncovering the functioning of group members, through group selfevaluation, could reduce dysfunction or lower the fear of it. Using a full scale intrinsic motivation inventory, we measured the impact of group self-evaluation on the quality of motivation over a 4year period with a total of 355 participants in a collaborative learning project in high schools (K11). We show that, compared to the control population, students exhibit a much more internalized motivation profile, with effect sizes in the range of medium to large for the different parameters. We conclude that group self-evaluation primes students for autonomous motivation. We suggest that the procedure should be applied systematically in substantial collaborative projects.
\end{abstract}


This study approaches collaborative learning in small groups from a Self-Determination Theory perspective (Ryan \& Deci, 2000a, 2000b). It takes the point of view that when students operate from autonomous motivation, when they are self-determined, they are more likely to take on a collaborative learning (or working) attitude. In this introduction we first describe collaborative learning and the ways in which collaborative effort can be stimulated, with special attention to group evaluation. Then we give a brief description of Self-Determination Theory and how perceived self-control, autonomy, contributes to autonomous motivation and how this, as a consequence, can promote collaborative effort. Finally, we describe the context of the study, high school education, and we formulate the experimental question.

\section{Collaborative Learning and Transactive Dialogue}

Collaborative efforts touches many aspects of daily life, whether it is children who play, people at work, community activities, sporting events or cultural manifestations. It also occurs in scholarly education, either implicitly, as a result of students' self-regulated learning initiatives, or explicitly, as in collaborative learning tasks. With collaborative we refer here to "the use of a selfcontained task and with the focus on joint activity with the object of creating shared understanding” (p177, Tolmie, et al., 2010). The strength of collaborative effort lies in the creation of conditions that lead to co-construction of meaning, a process that is mediated by constructive conflict, also referred to as constructive transactive dialogue or shared cognition (Blatchford et al., 2003, 2006; Garrison \& Akyol, 2015; Tolmie et al., 2010; Van den Bossche et al., 2006). Indeed, when students were asked about the main arguments for why collaboration had contributed to the success and enjoyment of their project, their unambiguous answer was: sharing. They expressed this in two fashions, sharing in the sense of comfort, sharing workload, skills and responsibilities, and in the sense of co-construction, developing shared knowledge through the exchange of thoughts and opinions (Kramer \& Kusurkar, 2017).

\section{Group Beliefs, Task Authenticity and Constructive Transactive Dialogue}

Whether or not group members engage in constructive dialogues, and to what extent, depends on a number of factors, including their perceptions of the interpersonal context of the 
group. Four beliefs (group-beliefs) have been identified that influence group working: psychological safety (inclusive group ethos, trust), cohesion (stay on task together), potency (collective efficacy or collective competence) and interdependence (crucial information comes from other group members) (Van den Bossche et al., 2006). For instance, when students are able to make unique contributions to a task or when the task is complex, they exhibit less social loafing (Harkins \& Petty, 1982). Social loafing is the phenomenon that participants put less effort, less engagement, into a group task compared to an individual task. Besides group beliefs, engagement also depends on whether students identify with the task; they must perceive the task as complex and relevant and not as "busy work". The authenticity of the task, that is, group projects that resemble real-life situations, is a determining factor in this (Asgari \& Dall'Alba, 2011; Barab et al., 2000; Blumenfeld et al., 1991; Larmer \& Mergendoller, 2010; Scager et al., 2016; Visser et al., 2017). In companies, identification with the task seems to be determined by the recognition of a “shared purpose” (Adler et al., 2011). It is fair to say that the necessary interplay between social and cognitive skills receives little attention in education, either in the construction of tasks, is it really necessary to work in groups (Larmer \& Mergendoller, 2010), or in the support of collaborative tasks, what can teachers do to steer students to positive group beliefs (Blatchford et al., 2003; Dijkstra et al., 2016).

\section{Collaboration Steered by Teacher Interventions}

What follows is that bringing people together around a task is a prerequisite but not a guarantee of collaborative effort (Chang \& Brickman, 2018). Johnson et al. (1998) therefore formulated five key elements, referred to as “internal dynamics”, which make collaboration work. These five elements overlap with factors that determine the aforementioned group beliefs. The elements are positive interdependence, individual accountability, face-to-face promotive interaction, employment of social skills and group processing. Individual accountability means that group members are responsible for their contribution to the group activity and for their acquired knowledge. It implies that individual performance is assessed and the results are fed back to the group and/or linked to an individual grade. The need for individual accountability is based on the findings that some people work better, or harder, when their input is also recognized outside the group (Slavin, 1996). Collective contexts that provide a great deal of information about 
individual contributions are perceived as more important to individuals than contexts that provide less information (or none) (Karau \& Williams, 1993), hence this may explain why students may make a greater effort. Moreover, students may find it unfair if non-productive members share the group grade (Freeman \& McKenzie, 2002). Anticipating unfairness may have a negative effect on engagement in subsequent collaborative tasks.

In order to promote collaboration, instructors may give students separate resources (jigsaw approach) (Mesch, 1991) and complementary roles thereby creating interdependence. Teachers may use individual tests to check if students had learned from their peers and use these test results in the calculation of the group grade (element of individual accountability). Teachers may also eavesdrop on groups and intervene if group members are not supporting each other. They may give instructions about problem solving techniques, and show how to communicate one's knowledge with peers or challenge students to reason their conclusions. Teachers must teach leadership, trust-building, decision-making and conflict-management skills (element of social skills). Finally, teachers must ensure that students take time to engage in group processing. They must observe how members have participated in stream-lining the learning process, how they have alerted group members of unskilled and inappropriate actions and what actions have been undertaken to improve the group work (Johnson \& Johnson, 2009). Collectively, group functioning instructions and individual tests are generally appreciated by staff and students and they facilitate collaborative effort, reduce social loafing, steer towards positive group-beliefs both in academic (Chapman \& van Auken, 2001; Gillies, 2004; Kao, 2013; Mello, 1993: Slavin, 1996; Strong \& Anderson, 1990) and in professional settings (Salas, 2008).

\section{Collaboration Steered by Group Self-Evaluation}

There are however limits to what a teacher can do and should do. For instance, individual testing is hardly feasible when the tasks are complex, open ended, and requiring different skills that are impossible to measure individually (Strong \& Anderson, 1990). Also, with respect to monitoring and correcting group functioning, in numerous occasions students will spent more time working on their task out of class than in class. Moreover, we repeatedly observed, as bystanders in evaluation sessions at school, that teachers have biased views of group functioning. Indeed 
several studies revealed that teachers differentiate their behaviors towards individual students based on their expectancies of those students (Domen et al., 2019; Harris \& Rosenthal, 1985). This is an undesirable situation for collaborative projects because it may force students, who now have the unique opportunity to express themselves differently, to resume the role they have been “assigned” in traditional class teaching. Finally, too much teacher involvement and too many instructions to make collaboration work contradicts a fundamental characteristic of collaborative learning namely that ownership and control of the learning should be given to the students (Blatchford, 2003). Importantly students at the end of high school or at the beginning of University are quite familiar with behaviors that lead, and do not lead, to productive collaborative efforts. The ground rules for group functioning that they propose (Kramer \& Kusurkar, 2017) are not short of what educators and psychologists have produced (for instance, Gillies, 2004). Although there is an undeniable role for group training (Salas, 2008), it is our opinion that whether students employ this knowledge, and even stick to ground rules they have proposed themselves, is largely determined by the importance they see in the learning task, the responsibilities they are given (Scager et al., 2016) and the way collaborative effort is evaluated.

As an alternative to the teacher-based interventions described above, group self-evaluation can be applied. In this evaluation, also known as group "auto-rating" (Brown, 1995) or "selfassessment" (Conway, 1993), group members either give an overall judgment of individual contributions, holistic approach, or they measure individual contribution against a set of rules, category-based approach (Brown, 1995; Conway, 1993; Lejk \& Wyvill, 2001a). The evaluation reports are then converted into individual weighting factors (IWF) which, when multiplied by the group grade, result in an individual grade. Group self-evaluation, when applied during and at the end of a collaborative task, addresses two elements of the internal dynamics mentioned previously (Johnson et al. , 1998), namely individual responsibility and group processing. Like for teacher-b ased evaluation, group self-evaluation encourages individual accountability because it is a way of uncovering individual contributions to the group effort. Self-evaluation may also influence group beliefs, it may lead to enhanced psychological safety and cohesion. Group self-evaluation does not go without a flaw, especially as a result of overly generous (to others) or overly selfpromoting students. Numerous studies have therefore considered mathematical strategies to better 
ensure the fairness of peer evaluation by limiting possible excesses in individual assessment (Goldfinch, 1994; Ko, 2013; Neus, 2011; Spatar, 2014). The overall results of these studies suggest that group self-evaluation works well and that the beneficial effect on group functioning more than compensates for any problems that may occur (Forsell et al., 2020; Freeman \& McKenzie, 2002; Kaufman et al., 2000; O’Neill et al., 2018; Weaver \& Esposto, 2012).

Research on the impact of group self-evaluation has focused primarily on the need for individual accountability and the sense of fairness experienced by staff and students (citations above). As for secondary or higher education, few studies deal with the potential beneficial effects on collaborative learning. Three studies report an increase in student engagement (Kench et al. 2009; Mello, 1993; Weaver \& Esposto, 2012) and one study reports that self-evaluation encourages equal contributions by group members and controls free-rides (Freeman \& cKenzie, 2002). An additional benefit of self-evaluation is that it gives students a good opportunity for selfcontrol, a sense of autonomy, the subject of this report.

\section{Self-Determination Theory, Autonomy, and Collaborative Attitude.}

From the perspective of Self-Determination Theory, self-control is important because it leads to a greater degree of perceived autonomy (Ryan \& Deci, 2000a, 2000b) and this impacts on the quality of motivation. Briefly, the Self-Determination Theory posits that the motivation for undertaking an activity in a self-determined fashion (with high volition) requires the fulfillment of three basic psychological needs, which are: a perceived sense of autonomy, competence and relatedness. Here, autonomy refers to the need for choice and the need to feel ownership for one's behavior, also expressed as a sense of agency and perceived internal causality (De Charms, 1968; Deci \& Ryan, 1985). Autonomy should not be confused with independence. The need for competence is generally understood as being the consequence of an inner necessity to produce desired outcomes, to experience a sense of usefulness and personal causation (Deci \& Ryan, 1980; White, 1959). Lastly, the need for relatedness pertains to the feeling of belonging to a group of friends or peers. The need for relatedness with significant others originates from studies dealing with interpersonal attachments, also known as identification with peers (Baumeister \& Leary, 1995; Reis, 1994). Autonomy has a special status among the three psychological needs because it is the vehicle 
through which the organization of personality proceeds and through which other psychological needs are actualized. Environments that warrant fulfillment of these needs are therefore said to be autonomy-supportive (Deci et al., 1994; Kusurkar et al., 2011; Kusurkar \& Croiset, 2015; Reeve \& Jang, 2006). The theory further posits that depending on the level of satisfaction or frustration of needs, motivation occurs in different qualities, ranging from amotivation, externally-regulated to intrinsic motivation (see figure S1, “Taxonomy of Human Motivation”, supplemental material) (Ryan \& Deci, 2000a, 2000b). External regulation can be further divided in two categories, where people work under external or internal pressure (controlled motivation, non-self-determined) or where people have identified or integrated the importance of the task (autonomous motivation, selfdetermined). The more people internalize their motivation the more they are self-determined and, as a consequence, self-regulated (Zimmerman, 1990 \& 2008). Internalization leads to a sense of wellness because of the integration of need satisfaction with goal setting (high level of congruence) (Ryan, 1995).

Important for collaborative learning, autonomous motivation is more conducive to the employment of adaptive interpersonal skills and mastery-oriented learning (Deci et al., 1981; Chapter 9, p216, Ryan \& Deci, 2017; described in “Relationship Motivation Mini-Theory” of Self-Determination Theory, chapter 12, p293, Ryan \& Deci, 2017; Vansteenkiste et al., 2004). An important adaptive interpersonal skill is perspective taking. This is the ability of group members to try to understand each other's thoughts and motives (Hoever et al., 2012). In mastery orientation, also known as learning goal-orientation (Smither et al., 2005), students are more inclined to want to understand the learning material, to get an inclusive picture. Thus, they will be more attentive to the input of other members, they will be more sensitive to feedback (from peers or instructors). We take the position that when group members are open to thoughts and motives of group members and adopt a masterly-oriented learning attitude, they also have à priori more positive group beliefs and will be more likely to engage in constructive transactive dialogue. Giving autonomy to the group members, expressed by students as "self-control” (Scager et al, 2016), is the main consideration why we chose to test the impact of a self-evaluation procedure in our collaborative projects. We distinguish two sentiments of autonomy in a group: the first deals with 
the freedom of choices offered by the learning task, to what extent is the task autonomy supportive. Collaborative learning tasks are generally considered autonomy-supportive because they fulfill the three needs of autonomy, competence and relatedness. Moreover, in collaborative learning tasks, there may be an additional sense of collective competence, where students are confident in the outcome of the task because they feel supported by the competencies of the group members (Kramer \& Kursurkar, 2017). The second sentiment of autonomy deals with group beliefs, to what extent is the group internal culture autonomy supportive? A key point in our argument is that the dysfunction of one member, for instance a free rider or a non-accepting dominant member, effectively removes control of group functioning from all members, even when the learning task is intended to provide students with a great deal of self-control. This perceived lack of control, as well as the possible anticipation of non-collaborative behavior, deprives members of perceived autonomy and thus has a negative effect on autonomous motivation and therefore may have negative consequences on how students operate in the group and how they experience the normally autonomy-supportive learning task (Aggarwal \& O'Brien, 2008; described in "Relationship Motivation Theory”, Theorem VI, Chapter 12, p311, Ryan \& Deci, 2017). A loss of autonomy can also lead to a loss of collective competence; students lack the need for sharing that is necessary to complete a complex task. We hypothesized that when students are

given the opportunity to evaluate their group, against criteria they have set themselves, it may not only reduce the risk of non-collaborative behavior (Williams et al., 1981) but it may also relieve some of the anxiety that it may cause. Both effects give the group more control over their functioning and should lead to a better learning experience. When students feel they have some control over the way their contribution is recognized and if they have some control over the way the contribution of other members is recognized, they feel more autonomous. In short, selfevaluation may stimulate adaptive interpersonal skills, may stimulate a collaborative attitude, through the intermediate of perceived autonomy.

\section{A Modified Group Self-Evaluation procedure}

The self-evaluation procedure that is the subject of this study is based on a category approach, but differs from those previously discussed (Brown, 1995; Conway, 1993; Lejk \& Wyvill, 2001a, 2001b), and from other online group-evaluation applications (O’Neill et al., 2018; 
Freeman \& McKenzie, 2002), in that students define their own rules, a minimum of five and a maximum of seven. Rules are discussed with the teachers, and teachers may give hints about characteristics of effective groups to spark discussion, but they are not imposed on the group. In addition, we did not attempt to correct the assessment of overly generous or self-promoting students, but created a second coefficient that reflects the coherence of the group evaluation. We reasoned that realistic self-evaluation is a good measure of the extent to which a group member is mindful of his or her functioning in the group. The research project was conducted at a secondary school, at K11 level with an average age 16.5 years, as part of a larger study program exploring how to make the transition from school to university better. One of the problems students indicate in surveys in the first year at our university is the high degree of self-regulation, which many say they cannot handle. What we are studying is whether or not school students are able to perform a complex task in groups on their own, that is, without constant input from teachers. The way the students handle self-evaluation, the quality of their motivation, and the final product of their group project, are measures that give a good impression of their self-regulatory abilities. These results can play into the analysis of the problems that students express in the first year.

\section{Research Question}

The question we ask in this study is whether group self-evaluation impacts positively on the quality of motivation. The primary hypothesis is that there is no significant difference in the quality of student motivation when implementing a group self-evaluation procedure. The

secondary hypothesis is that the tested parameters have significant differences and self-evaluation has an impact on the quality of motivation. We tested the self-evaluation procedure in a high stake collaborative learning task, lasting one semester, of which the result contributes to the diploma of the final year (baccalauréat). As teachers, we think it is important that the test ground has a high reality value. In both control and experimental classes, we measured motivation with a full scale Intrinsic Motivation Inventory (IMI). This multiscale survey measures the extent to which students: were interested or enjoyed the task, valued or found the task useful, experienced choices, felt competent, felt pressure or tension, made an effort and found the task important, and experienced a sense of relatedness with group members (Ryan \& Deci, 2000a, 2000b). 


\section{Methods}

\section{Participants Characteristics, Ethics and Assignment}

The participants were students at secondary schools with an average age of $\mathrm{M}=16.25$, SD $=0.5$. The population comprised $53.8 \%$ women and $46.2 \%$ men. They were in their $2^{\text {nd }}$ year $(K 11)$ of preparation of the "scientific baccalauréat" a diploma equivalent of an American High School diploma or an English GCE A-levels. Students prepare this diploma for three years at a "Lycée”. In total, 355 participants were involved separated over 12 classes: 7 control classes $(\mathrm{n}=224$, without intervention) and 5 experimental classes $(n=131$, with whom we carried out a group selfevaluation procedure) (table 1).

The studies have been reviewed and approved by the presiding officers of the schools and the Rectorat de l’Académie de Bordeaux, the governing body of the school inspection.

We studied the effect of the self-evaluation procedure in 3 different secondary schools over a period of 4 years. School 1 contributed from the beginning, 2015, school 2 joined in 2016 and school 3 in 2017 (table 1). The assignment of schools and of the classes involved was entirely determined by the willingness of biology and physics teachers to participate in the experimental study. The choice of K11 was dictated by the fact that this year of study included a high-stakes collaborative learning project. There were no other assignment- or selection criteria. The overall academic performances varied slightly between the schools. We were able to collect data from 2016 to 2018 and there were significant differences between student performances of the three schools, $F(2,246)=12.331, p<0.01$. A Tukey post-hoc revealed that semester grades of school 1 were significantly better than those of school 2 and $3(p<0.01)$, and school 2 and 3 were equal $(p$ $=$.089) (see table S3 in online supplemental material). We pursued the study over a period of 4 years for the following reasons: 1) to ensure that we had control and experimental conditions in each school (rotation scheme) so as to reduce possible confounding effects from predominant school cultures; 2) to have enough sample size for discerning significant effects; and 3) to measure how reliable the impact of the group self-evaluation procedure is on the student's perception of the project (can we repeat the same findings with time). As for student's academic performance, the 
use of a rotation scheme evened out the school differences described above. We obtained a similar control and experimental population. Over the period of 2016-2018, the semester grades (on a scale of 20) of 136 participants that had finished the semester in the control classes $(M=13.30$, $S D=2.19)$ were similar to the 113 participants in the experimental classes $(M=13.35, S D=$ 1.96), $t(247)=-0.193, p=.424$. We had no access to results of 2015. Given the imposed restrictions, we qualify the rotation scheme "as good as possible”. It has, however, one important advantage in that it reduces cross-talk between classes. Giving the impossibility to mask the experimental procedure, if we randomly divided classes into two, to obtain control and experimental groups, students' perceptions of the collaborative project would be strongly influenced by what they hear from their classmates.

Table 1. School Rotation Scheme With the Numbers of Students and Accompanying Teachers Involved in Control and Experimental classes.

\begin{tabular}{|c|c|c|c|}
\hline & Year & Control condition & Experimental condition \\
\hline \multirow{4}{*}{ SCHOOL 1} & 2015 & $\begin{array}{l}\text { Teachers B6, P4 (34 students) } \\
\text { Teachers B7, P5 (29 students) }\end{array}$ & Teachers ${ }^{1}$ U1, B1, P1 (14 students) \\
\hline & 2016 & Teachers $^{1}$ U1, B1, P1 (36 students) & \\
\hline & 2017 & Teachers U1, B5, P4 (22 students) & Teachers $^{3}$ U1, B3, P7 (30 students) \\
\hline & 2018 & Teachers ${ }^{3}$ U1, B3, P7 (34 students) & \\
\hline \multirow[t]{4}{*}{ SCHOOL 2} & 2015 & & \\
\hline & 2016 & & Teachers U1, B2, P2 (32 students) \\
\hline & 2017 & Teachers $^{2}$ U1, B2, P6 (34 students) & \\
\hline & 2018 & & Teachers $^{2}$ U1, B2, P6 (31 students) \\
\hline \multirow[t]{4}{*}{ SCHOOL 3} & 2015 & & \\
\hline & 2016 & & \\
\hline & 2017 & Teachers ${ }^{4}$ U1, B4, P3 (35 students) & \\
\hline & 2018 & & Teachers ${ }^{4}$ U1, B4, P3 (24 students) \\
\hline
\end{tabular}

Note. Identical Teacher Teams Are Indicated With ${ }^{1,2,3,4}$. B, Biology; P, Physics; U, University Teacher. 


\section{Description of the Collaborative Learning Project (TPE)}

The collaborative project, named “Travail Personnel Encadré” (TPE), or “Supervised Personal Project”, was designed and planned in the French national curriculum by the Ministry of National Education (Ministère de l'Education Nationale) with the intention to give students the opportunity to work autonomously in small groups on a project of their choice (chosen from a large list of social themes formulated in the government instructions) with an additional requirement that they had to integrate biology with one other discipline (physics, chemistry, mathematics or social sciences). According to the instructions of the Ministry the project is meant to be autonomy-supportive and serves to prepare students for a more self-regulating learning style that would be necessary to succeed in higher education. The TPE is a high stakes collaborative project because the project-grade is part of the diploma they obtain at the end of the 3rd (K12) year (“scientific baccalauréat”).

The project groups can be described as "student project groups" with the characteristics of: low authority differentiation, moderate temporal stability (one semester), and, at the onset, member interchangeability and a lack of skill differentiation (Hollenbeck et al., 2012). Students were asked to form groups of 2 to 4 students by personal choice (students sought their partners, groups were not allocated by the school). A large majority of groups (86\%) consisted of 3 members. Groups worked on their project throughout the autumn semester, corresponding to 15 weeks, with formal work sessions of 2 hours held in computer-cluster rooms each week. These dedicated work sessions were accompanied by one biology and one physics teacher of the school. These teachers provided the necessary cognitive scaffolding in scheduled bi-weekly get-togethers with the groups, in which questions were asked and suggestions given (scheduled tutorship). The first tutorial typically dealt with which societal issue was being studied (examples are pollution, mobility, global heating, urbanization, hygiene and infection, food supply for a growing world population, nutrition and, health), what was the problematic, and how did the students approach it? At a later stage teachers assisted in discussing and validating the integration with one of the other disciplines. The tutorial sessions took the form of structured debriefings (Eddy et al., 2013). Important discussion topics to promote group work in all but the first tutorial were; (a) reflection and self-explanation; (b) data verification, feedback, and information sharing; and (c) goal-setting/action planning and d) task 
delegation (Eddy et al., 2013). The work sessions offered enough time to also respond to questions that arose in the groups (in addition to the planned get-togethers).

The above described conditions were identical for control and experimental classes. Additional activities for the experimental classes are discussed in the next section ("Experimental Intervention”). For most of the classes involved in this study, the university teacher (IJK) participated in both control and experimental conditions and was available for group questions and was involved in the scheduled tutorship. This way the university teacher became a systemic independent-variable and this should eliminate possible bias in the perception of the project between control and experimental classes. The set of accompanying teachers is referred to as the "teacher-team" (see table 1). Lastly, we mention that project groups were encouraged to seek expert support outside the class room, for instance from other teachers, university laboratories, companies or learned societies. The groups prepared a written report (printed or in pdf format) and they prepared an oral presentation. Both products were graded by yet another pair of biology and physics teachers.

\section{Experimental Intervention}

\section{Group Self-Evaluation Procedure in Brief}

The group self-evaluation procedure employed in the experimental classes qualifies as an “informational external-intervention” (Deci \& Ryan, 1980, 1985; described in Chapter 6, p130, Ryan \& Deci, 2017). It is an experimental manipulation without randomization (American Psychology Association, 2020). The intervention comprised four elements: (a) A brief instruction about the many challenges of collaborative projects and about the Intrinsic Motivation Inventory at the end of term, (b) the drafting of team-functioning rules ("ground rules"), (c) a progress evaluation with a group self-evaluation at midterm and, (d) a group self-evaluation at the end of term. The control classes did not receive this information and the groups were not evaluated. However, they were informed of our goal to measure participants' subjective experiences after task participation with a full-scale IMI.

\section{A Brief Instruction About the Many Challenges of Collaborative Projects}


The university teacher (IJK) gave a 15 minute presentation in the first tutorial session about group functioning and its major challenges: achieving the task, constructing and maintaining group effort and taking into account the individual needs of group members (Asgari \& Dall'Alba, 2011). They were also informed that task delegation should take into account the different personalities within the group; taking benefit of social, cerebral or extrovert traits. Finally, the students were informed about group dynamics in which the emphasis was placed on possible disruptions that may occur within the group when: making strategic decisions (direction of the project), co-constructing knowledge (constructive conflict), delegating necessary tasks, controlling time limits or when members do not comply with the ground rules (Tuckman \& Jensen, 1977; Van den Bossche et al., 2006). (Information about the brief instruction can be found in online supporting material, slides “collaborative learning: group working”)

\section{Start of Project: Setting the Ground Rules}

In the first tutorial session, students were given time to form groups, discuss their project and prepare a set of 5 to 7 ground rules. These numbers were chosen for two reasons: firstly, in prior experiences students spontaneously came up with 5 rules and, secondly, this number allows for a nuanced, less subjective, evaluation of the group members. Students hardly ever came up with 8 rules and more rules would unnecessarily complicate the evaluation. The ground rules are converted into questions (see figure 1a) and are fed into a web-based self-evaluation application.

Figure 1. One example of Ground Rules Formulated by Students and Two Examples of Group Functioning Reports, "Dashboard", after Midterm Self-Evaluation. 


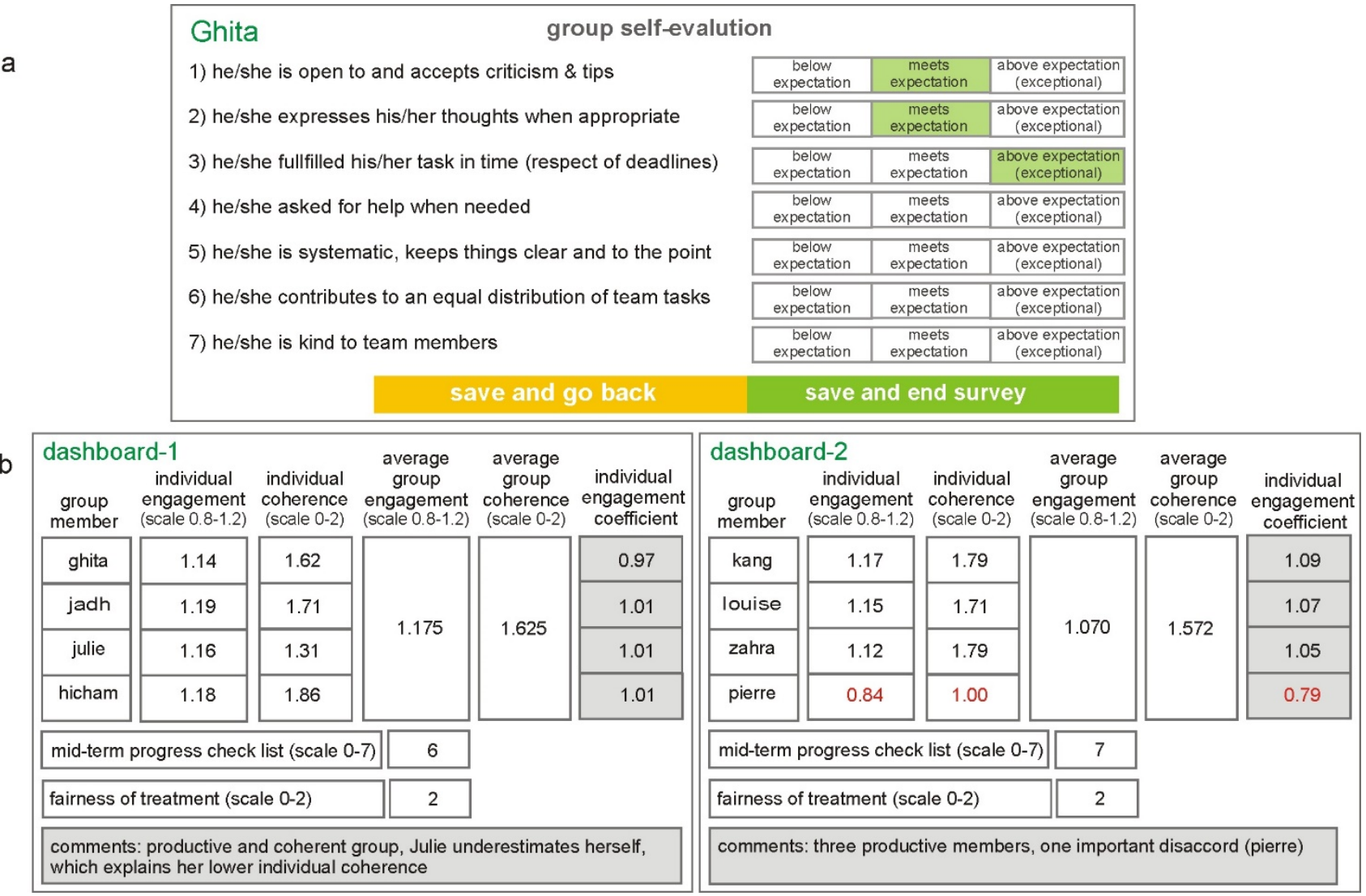

Note. a) The ground rules produced by the students are converted into questions in a web-based application. Group members vote on their own compliance with the rules and that of the other members. We typically offer three levels of compliance (below expectation, satisfactory or above expectation).

Note. b) The report informs the groups about how well their members adhere to the rules ("individual engagement"), which serves as a measure of engagement in the collaborative effort, and it informs to what extent the opinion about themselves correspond with that of other members ("individual coherence"). The report also reveals the "average engagement" and "average coherence" of the group. The "individual engagement coefficient" represents the individual engagement relative to the average group-engagement and it determines the individual project grade (coefficient $x$ project grade). The two reports show an example of a productive and coherent (dashboard-1) and a productive but not coherent group (dashboard-2), where three members carry the workload (adhere to the rules) of a team of four.

Our reasoning for creating the ground rules themselves is that students understand their own criteria better than those prescribed by the teacher, the criteria are more likely to be appropriate for the collaborative task in question and groups that establish forward-looking agreements about how they want to work together were shown to be more focused and motivated to implement self-corrections or make adjustments to team processes (DeChurch \& Haas, 2008). The process normally took 30 minutes. 


\section{Midterm: Progress Report and First Group Self-Evaluation.}

The midterm structured progress-survey (after-action review) comprised a list of 9 questions dealing with the title and the problematic of the project, whether the group had reached the level of task-delegation, whether they had found external experts and had thought of an experiment to enrich their project (optional). They were also asked to provide examples of pertinent documents and websites that they had consulted for their research. Lastly, the groups were asked whether they felt fairly treated by the project-associated teachers. Information about the midterm progress survey can be found in online supporting material, table S1)

In the self-evaluation procedure, group members qualify their own compliance with the ground rules and that of other group members. Students could tick three boxes for each ground rule: below expectation, satisfactory or above expectation (figure 1a). Teachers could set coefficients for these qualifications and we had chosen 0.8, 1.0 and 1.2 respectively. This meant that students who did not comply with the ground rules at all, would only get $80 \%$ of the project grade. Exceptionally compliant students, could rise to $120 \%$. The individual engagement is calculated by the number of points divided by the number of ground rules. Values are in between 0.8 and 1.2. We thought it wise to restrict the scale to abovementioned limits because the aim was neither to punish, nor to glorify certain group members (Cheng \& Warren, 2000; Kilic \& Cakan, 2006). The autoevaluation procedure was meant to give students a sense of agency with respect to the functioning of the group and to give each other insight in a most objective way. Inter-rater coherence was calculated by comparing self- with other member evaluations. The difference is 0 (same appreciation), 1 (difference of only one level of the scale) or 2 points (difference between below satisfaction and above expectation for the same rule). The application counts the differences and divides them by the number of ground rules. Individual coherence values are presented as 2 minus the delta value. The same applies for the calculation of the "group average coherence".

The programme creates a report, (“dashboard-1 and -2” in figure 1b) of the self-evaluation procedure that informs staff and students about compliance with the ground rules ("individual engagement”) and about the coherence of the respective evaluations (“individual coherence”). Rather than correcting for inter-rater disagreement we informed the students about the coherence 
of their evaluation and, in case of disagreement, whether this was due to over- or under appreciation of their own performance (Leik \& Wyvill, 2001b; Neus, 2011). Coherence is important because groups can only repair dysfunctioning if all members agree on their functioning. The report also shows an "individual engagement coefficient" which is the equivalent of an individual weighting factor (IWF). It is simply measured as the "individual engagement" divided by “average group engagement”. The mid-term evaluation was informative. Its purpose was to familiarize the students with the application (how to access the site and how to vote), to make them aware of how their votes were translated into scores of group functioning, and to inform them about how they functioned in the eyes of their groupmates. The instructors informed their groups about the meaning of the results and were open to questions and suggestions when asked by the groups. In addition to familiarizing group members with the evaluation procedure, there is evidence that a mid-term evaluation with individual feedback has a positive effect on cooperation (Archer-Kath et al., 1994).

\section{End of Term: Second Group Self-Evaluation.}

The group self-evaluation procedure was repeated at the end of term, at the time students formally submitted their written report. This self-evaluation was given a grade: the "individual engagement coefficient” was used for the calculation of the individual project grades (coefficient X group grade $=$ individual grade) .

\section{Measures}

In order to answer our research question, whether the group self-evaluation procedure impacts on the quality of motivation, we asked students to complete a paper-version of a full scale Intrinsic Motivation Inventory (IMI) when they handed in their project reports (Deci et al., 1994; McAuley et al., 1989). The survey was anonymous and students were informed that participation was voluntary and that taking part or not had no impact on their project grades. All students had participated in the survey. There were 1.69\% incomplete submissions (6 participants), which were omitted in data processing. The IMI is a multidimensional scale survey intended to measure the subjective experiences of participants following task participation (Ryan, 1982). Various iterations 
of the IMI have been in use for more than 30 years, with well-established validity and subscale reliability across tasks, conditions, and settings (McAuley et al., 1989). The original questionnaire, developed by Ryan and Deci, and relevant literature can be retrieved from the Self Determination Theory website (http://selfdeterminationtheory.org/intrinsic-motivation-inventory/). The scale has seven primary subscales, detailed below, that can be mixed and matched to suit research needs. Our french anchor points for the rating scale were: Pas de tout d'accord / pas d'accord / plutôt pas d'accord / indifférent / plutôt d'accord / d'accord / tout à fait d'accord.

Although referred to as the IMI, the survey measures more than just intrinsic motivation; it covers a range of criteria that indicate whether or not students adopted a self-determined learning approach (autonomous or internalized regulation of behavior). For a brief explanation of regulation of behavior we refer to figure S1 "taxonomy of human motivation" and its caption in the online supplemental material. The survey probes the perception of “choice”, a key predictor of perceived autonomy and thus of autonomous (self-determined) regulation. It also measures 2) “interest/enjoyment”, a self-report measure of intrinsic motivation, 3) perceived "competence” a measure of competence, 4) “effort/importance”, predictor of competence and autonomous motivation, 5) “pressure/tension” negative predictor of autonomy and of intrinsic motivation, 6) “value/usefulness”, measure of relatedness to the subject and a predictor of autonomous motivation and, 7) relatedness, a measure of social relatedness. The questions were adapted for the TPE project, which means that they were specifically related to the project, and translated into French with the help of a French biology teacher. In order to verify whether the questions of the French version resembled the original meaning, one of the members of the Language Department at the University of Bordeaux translated them back into English. Three questions had to be rephrased until agreement was obtained. This is a best practice procedure prescribed for crosscultural use of self-report questionnaires (Beaton et al., 2000). (See Table S2 in online supplemental material for the French version of the IMI.)

The data from the IMI were collected as shown in Table S2 in online supplemental material. Values greater than 4 (for interest/enjoyment, perceived competence, effort/importance, perceived choice, value/usefulness and relatedness) are considered as positive predictors of self- 
determination. Pressure/tension is a negative predictor of autonomous motivation and the value should be below 4 if students felt self-determined.

\section{Statistics and data analysis}

\section{Psychometrics}

The validity of the IMI had been established previously (McAuley et al., 1989). With respect to internal consistency, a subscale reliability analysis was applied and we obtained good reliability for all subscales, with Cronbach alpha values within the range of 0.811 to 0.886 which corresponds to robust/reliable.

\section{Analytical Strategy for Impact of Experimental Intervention}

The impact of the self-evaluation procedure (also referred to as the "experimental intervention”) was analyzed in different ways. The statistical analyses were performed with the 3.5.1 version of the R software (R Core Team, 2018), completed with the "car" 3.5.1 and the "mosaic" 3.5.3 packages. We started by accumulating the average scores of the IMI subscales of all control and all experimental classes over a period of 4 years. In first instance, we used a one way multivariate analysis of variance (MANOVA) to see if there were significant differences in the way the two student populations, control versus experimental, appreciated the collaborative project. This was followed by Student's unpaired t tests to analyze which specific subscales of the IMI were significantly different between control and experimental classes. We applied Hedges' calculations ( $g$-value) to estimate the effect sizes of the intervention on the outcome of each of the IMI subscales (Stangroom, 2018). Effects size is qualified as large when the $g$-value is 0.8 or more, medium when it is in between 0.2 and 0.8 and small when it is 0.2 or less. In addition to looking at differences in mean values of the survey results, we also examined whether the intervention had an effect on the distribution of variance of the IMI results. We considered this a good way to see how homogeneous the project experience was. To do this we compared variance between control and experimental classes and employed a Brown-Forsythe test calculate possible significance (function “Levene” test on R project). 
In order to verify the possible interaction between the intervention and other factors, such as the contribution of years, schools and teachers to the students' perception of the collaborative project, we used a model III two-way-analysis of variances (ANOVA). By interactions we mean other factors that can modulate the effect (in direction or magnitude) of the experimental intervention on IMI scores. For instance, school-culture (which is an ensemble of teacher and student attitudes towards collaborative projects) may amplify or diminish the impact of the procedure on students' perception of the project. Likewise, important political events may play a role in how students perceive the project and this would mean that the impact varies from year to year. In the case we did not observe significant interactions, a model II two-way ANOVA was performed. When significant interactions between the intervention and another factor were found (school, year or teacher team) or when we observed a significant effect of the intervention on the IMI score, the corresponding post-hoc pairwise comparisons were analyzed with a Tukey HSD test.

\section{Confidentiality}

In both control and experimental groups, at the onset of the TPE project, students were informed by the University teacher (IJK) about the exchange programme between institutions and about the purpose of the study, namely to find out how they perceived the collaborative learning project. As mentioned earlier, participation in the IMI was voluntary and anonymous. They were also informed that the information, on a collective level, could be used for a scientific publication.

\section{Results}

\section{Group Self-Evaluation Significantly Raised the Quality of Motivation}

We wanted to examine whether group self-evaluation had an impact on how students perceived an autonomy-supporting collaborative learning task (TPE). For this purpose, we used a full scale Intrinsic Motivation Inventory. Despite the pedagogical and didactical intentions that had laid the foundation for the collaborative learning project (TPE), we were surprised to see that the IMI 
scores of the control classes revealed that not all students perceived the project as intended (table 2).

Table 2. Response Scores for Each Subscale of the Intrinsic Motivation Inventory in Classes Without (Co) and With Group Self-Evaluation (Exp)

\begin{tabular}{|c|c|c|c|c|c|c|c|c|c|c|c|c|c|c|}
\hline & \multicolumn{2}{|c|}{$\begin{array}{c}\text { interest } \\
\text { enjoyment }\end{array}$} & \multicolumn{2}{|c|}{ choice } & \multicolumn{2}{|c|}{$\begin{array}{c}\text { value } \\
\text { usefulness }\end{array}$} & \multicolumn{2}{|c|}{ competence } & \multicolumn{2}{|c|}{ relatedness } & \multicolumn{2}{|c|}{ effort } & \multicolumn{2}{|c|}{$\begin{array}{l}\text { pressure } \\
\text { tension }\end{array}$} \\
\hline & co & exp. & co & $\exp$ & co & exp & co & exp & co & $\exp$ & co & exp & co & exp. \\
\hline $\bar{x}$ & 4.71 & 5.41 & 4.90 & 5.90 & 4.73 & 5.56 & 4.85 & 5.31 & 5.89 & 6.29 & 5.96 & 6.29 & 3.92 & 3.49 \\
\hline SD & 0.993 & 0.824 & 1.387 & 1.096 & 1.353 & 1.080 & 0.952 & 0.0824 & 1.329 & 0.942 & 1.083 & 0.926 & 1.695 & 1.385 \\
\hline \multicolumn{15}{|c|}{ Significance of differences between the variance of control and experimental classes (Brown-Forsythe test) } \\
\hline & \multicolumn{2}{|c|}{$\mathrm{p}=.08164$} & \multicolumn{2}{|c|}{$\mathrm{p}=.00108^{* * *}$} & \multicolumn{2}{|c|}{$\mathrm{p}=.00063^{*} * *$} & \multicolumn{2}{|c|}{$\mathrm{p}=.16590$} & \multicolumn{2}{|c|}{$\mathrm{p}=.00422^{* * *}$} & \multicolumn{2}{|c|}{$\mathrm{p}=.01958^{* * *}$} & \multicolumn{2}{|c|}{$\mathrm{p}=.00321^{* * *}$} \\
\hline
\end{tabular}

Whereas the mean values are above the middle (or neutral) point of the Likert scale, some 25\% of the students had nevertheless not perceived much “choice”, "value/usefulness” and “interest/enjoyment”. For pressure/tension, nearly half the population had selected values above the middle point. As examples, whereas the project really offers lots of choice, the students hardly perceive it as such $(\mathrm{M}=4.90, \mathrm{SD}=1.387)$. The project was meant to prepare students for a more self-regulated learning attitude for the University but they saw little value or usefulness in the exercise $\mathrm{M}=4.73, \mathrm{SD}=1.353)$ and they only moderately enjoyed the project $(\mathrm{M}=4.71, \mathrm{SD}=$ 0.993).

The perception was considerably better in the experimental classes where we used the group selfevaluation procedure. When accumulating the results of all control ( 7 classes, $n=224$ ) and experimental classes ( 5 classes, $n=131$ ), we observed important increases in the outcome of the IMI with the exception of “pressure/tension”, which was reduced (table 2, row 3). We performed a one-way multivariate analysis of variance and revealed that indeed there were significant differences between control and experimental classes, $F(7,336)=9.75, \mathrm{p}<.01$; Pillai $=0.169$. We employed student's unpaired t tests, to analyze which specific IMI subscales were significantly different because of the intervention and showed that all subscales were concerned. 
Table 3. Effect Size of Group Self-Evaluation on the Response Scores of the Intrinsic Motivation Inventory

\begin{tabular}{|l|l|}
\hline IMI subscale & $\begin{array}{l}\text { Effect size } \\
\text { (Hedge's } g \text { ) }\end{array}$ \\
\hline Interest/Pleasure & $(+) .805$ \\
\hline Choice & $(+) .692$ \\
\hline Value/Usefulness & $(+) .688$ \\
\hline Competence & $(+) .575$ \\
\hline Relatedness & $(+) .389$ \\
\hline Effort/Importance & $(+) .302$ \\
\hline Pressure/Tension & $(-) .248$ \\
\hline
\end{tabular}

Note. Positive Hedge's g values indicate an increase in the values for the experimental classes, and negative values indicate a decrease for the experimental classes.

Besides significant differences in mean values we also noted a systematic reduction in standard deviation (SD) values of the IMI scales from the experimental classes (table 2, row 4). We therefore calculated the significance of differences in variance for each subscale with the BrownForsythe test. We observed a significant reduction in variance in the experimental classes for subscales “choice” $(p<.01)$, “value/usefulness” $(p<.01)$, “relatedness” $(p<.01)$, “effort” $(p=$ $.020)$ and “pressure/tension” ( $p<.01)$, but not "interest/enjoyment” ( $p=.08)$ and “competence” ( $p$ $=$.17) (table 2, row 6). These results imply that the students had a more homogeneous appreciation of the collaborative project under the condition of self-evaluation (exp).

We next applied Hedges' calculations to estimate the effect size and found large and medium effects for all subscales, with "interest/enjoyment”, “choice” and "value/usefulness” ranking in the top 3 (table 3). 


\section{Analysis of Interaction with Teacher-Team Paired Classes Only}

We conducted several statistical analyses to determine what other factors, besides the experimental intervention, could possibly influence the results of the IMI survey. We began by examining the possible influence of the composition of the teaching team (consisting of a biology, physics, and university teacher). To measure this, we compared the IMI results of control and

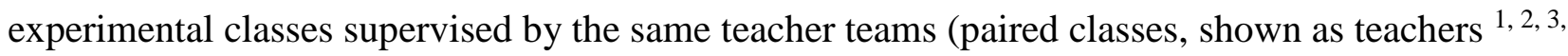
4 in Table 1). The total number of subjects decreased significantly, with 139 control and 99 experimental students distributed among 4 sets of supervising teacher teams (for numbers see Table 4, columns “teacher-teams paired classes"). With these reduced numbers, using Student $\mathrm{t}$ tests with Welch correction, we still observed significant changes in responses between the control and experimental classes with the exception of "relatedness", where $t(225.3)=0.98, p=.33$.

We next set out to find to what extent teacher-teams influence the amplitude of the impact of the intervention. We employed model III ANOVA tests, and observed significant differences. There was a significant experimental intervention/teacher-team interaction for "interest/enjoyment", $F(3,220)=5.02, p<.01$. A Tukey post-hoc test revealed that this concerned teacher-teams 2 and 4, where the procedure has a significant stronger positive impact on “interest/enjoyment” ( $p=.03)$. Significant interactions were also found for "competence",

Table 4. Student Numbers in Full and Reduced Data Sets Used for the Analyses of Possible Interactions Between the Experimental Intervention and Teachers, Years, or Schools

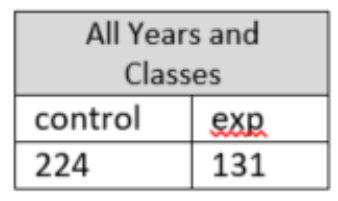

\begin{tabular}{|c|c|}
\hline \multicolumn{2}{|c|}{$\begin{array}{l}\text { Teacher-Team } \\
\text { Paired Classes }\end{array}$} \\
\hline control & $\exp$ \\
\hline 36 & 14 \\
\hline 34 & 31 \\
\hline 34 & 30 \\
\hline 35 & 24 \\
\hline 139 & 99 \\
\hline
\end{tabular}

\begin{tabular}{|c|c|}
\hline \multicolumn{2}{|c|}{ Year } \\
\hline control & exp \\
\hline 63 & 14 \\
\hline 36 & 32 \\
\hline 91 & 30 \\
\hline 34 & 55 \\
\hline 224 & 131 \\
\hline
\end{tabular}

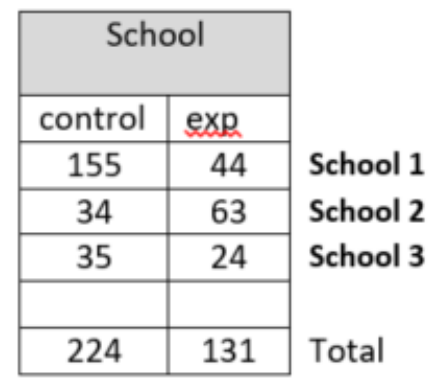

"effort/importance" and "value/usefulness" with $p<.04$ for each analysis. A Tukey post-hoc test revealed that this concerned team 4 , where the procedure has a significant stronger positive impact 
on these three subscales $(p<.03)$. We note that in these type III ANOVAs we lose all significant effects of the intervention except for its negative effect on "pressure/tension". This loss may be explained both by the decrease in the sample size and by the relatively low power of type III analyses for the study of main effects of factors.

\section{Analysis of Interaction with Year and School}

In order to verify if year and school could possibly explain the differences in outcomes of the IMI, we studied possible interactions in a similar fashion as described above. We found no significant interactions between "intervention" and "year" for any of the subscales ( $p>.34$ for each of the 7 subscales in a two-way model III ANOVA). We next verified if this still holds true with a more powerful model II ANOVA (Langsrud, 2003). Although there are significant variations of IMI scores between the years for each subscale $(p<.02)$, with the exception of "effort/importance", we still discerned a significant impact of the experimental intervention for all the subscales except "effort/importance", where $F(1,337)=3.35, p=.07$ (type II ANOVA). When applying the same analysis for the interaction between the intervention and school, we observed significant interactions with "effort/importance" and "choice”, meaning that the amplitude of the impact of the self-evaluation procedure is school-dependent for these two subscales. In this two-way model III ANOVA analysis we lost significance for the impact of the intervention on the IMI scores of "relatedness" (the dataset is much reduced). We also found significant differences in the IMI scores of the schools with respect to "value/usefulness" and "relatedness"; again, all schools were not equal.

\section{Conclusion and Discussion}

Our data show that not all students necessarily perceive a collaborative-learning task, which in principle should satisfy the necessary psychological needs, as autonomy-supportive. Some $25 \%$ of the students had not perceived much "choice”, "value/usefulness” and “interest/enjoyment” and 50\% experienced considerable "pressure/tension”. In particular, the perceived lack of choice is remarkable in a task that offers an awful lot of choices. The participants had a significantly better perception of the collaborative project when we applied a 
group self-evaluation procedure in which members set their own ground rules and evaluate themselves against those rules. We observed a large positive effect on “interest/enjoyment”, a medium positive effect on "choice”, “value/usefulness”, “competence”, “relatedness” and “effort/importance” and a medium negative effect on "pressure/tension”. In addition, we observed a much more homogeneous appreciation of the collaborative project, the distribution of variance was significantly reduced for “choice”, “value/usefulness”, “relatedness” and “pressure/tension”. However, all schools and teacher-teams were not equal, the amplitude of student responses to the intervention varied between schools and between teacher-teams (the two are naturally connected). In particular, students’ perceived “interest/enjoyment”, “competence”, “effort/importance” and “value/usefulness” were teacher-team sensitive. Moreover, when controlling for teacher-teams we lost a significant impact of the self-evaluation procedure on "relatedness" and when controlling for schools we lost significant impact on "effort/importance” and "relatedness". This loss can be explained in part by low numbers of students in each group but also by the observation that these two subscales already had very high values in the control classes. There simply was very little room to improve. Collectively, the tested parameters have significant differences between control and experimental classes and we can refute our primary hypothesis. We therefore conclude that group self-evaluation steered students towards a more autonomous motivation.

From the perspective of Self-Determination Theory, we explain the positive effect of group selfevaluation through a greater perception of autonomy. Although the perception of autonomy has been much studied in individual learning tasks, it is also important in group projects. Indeed, in addition to the student-instructor or student-task relationship, a second factor, the sense of control within the group, comes into play here. The collaborative learning task may in itself offer many choices, and the instructor may leave the group much freedom, group members will not experience these choices and this freedom, or experience them less, if they are dominated by one or more group members or if they are confronted with free riders. The same is true of a lack of individual accountability; it deprives participants of control over how their contributions are valued. Group self-evaluation gives group members a greater sense of agency, a greater sense of autonomy. Our finding that the distribution of variance in the survey results was significantly reduced in the experimental classes, also for the subscale "choice" which is a key predictor of 
perceived autonomy, indicates that not all participants are equally sensitive to the potential problem of control. We explain this result by assuming that the group self-evaluation procedure eliminated a priori strong negative feelings about collaborative learning only in a subpopulation of the students.

\section{Implications for Practice}

We believe that, in the interest of students, group self-evaluation should be applied in a collaborative learning task, or a sequence of tasks in the same group, that takes 20 hours of work or more. From a pedagogical point of view, dealing with students' values and attitudes, the gain is important because students with positive collaborative experiences, another important output besides task achievement (Hackman \& Morris, 1975), are more likely to wholeheartedly engage in new opportunities, at school, university or at the work floor. Given the important didactic value of group learning, be it cooperative or collaborative (Johnson et al., 1998; Johnson \& Johnson, 2009; Slavin, 1996), positive experiences can have a significant impact on students’ longer term personal growth and well-being (Ryan \& Deci, 2000a, 2000b).

As mentioned earlier, our procedure does not correct for over- or under-rating group members, but adds a second coefficient indicating the degree of coherence between self- and peer assessment. We note that much of the problem of over- or under-rating in our classes was resolved after the formative self-evaluation at midterm. The evaluation-report informed students the reason for incoherence, which member was concerned, and in almost all cases this was corrected in the second self-evaluation at the end of term. This correction may in part be the consequence that students wish not to penalize themselves or others in a summative setting (Sridharan et al., 2019). In addition, there is evidence that a midterm evaluation with individual feedback has a positive effect on team internal dynamics; students may have taken on a different attitude (Archer-Kath et al., 1994; Gabelica et al., 2012). We also note that although we encourage students to vote confidentially and the procedure provides opportunity for confidential voting, some groups take a collective approach and agree to rate all members equally. We do not see this as a problem. We foresee that when the self-evaluation procedure is applied in a number of collaborative projects, with different groups and for a number of years, personality traits could be distinguished. “Group 
leaders” would be characterized as those who regularly, and with a high degree of coherence, received high marks for their compliance with the ground rules. The self-evaluations may also reveal problematic individuals, where compliance is weak and linked to incoherent group appreciation. We recently discovered that a similar approach is taken in SPARKplus (for Self and Peer Assessment Resource Kit) at the University of Technology Sydney, Australia. Their selfevaluation report reveals two similar evaluation factors; an individual weighting coefficient, which they name the Relative Performance Factor (RPF) and a coherence coefficient, which they name the Self-Assessment Peer-Assessment factor (SAPA) (Freeman \& McKenzie, 2002; SPARKplus, n.d.). To our knowledge, SPARKplus has not been subjected to studies on student motivation.

In an ideal situation, group self-evaluation reports could form part of an apprentice portfolio (for instance in a section about "transferable skills"). Within the constraints of an educational environment, with its obligation to evaluate and qualify (quantify) knowledge and skills, a group self-evaluation procedure probably exercises the least external control. As such it sets the conditions that are favorable for productive collaborative efforts and mastery goalorientation (working for personal growth and not for a grade). Lastly, the procedure has been applied, but not tested for its impact, in collaborative projects at two universities where students created collective science-writing blogs. The IMI scores were very high (Kramer \& Kusurkar, 2017), students had operated in an intrinsically motivated fashion. Also, till date, for approximately 168 groups involving 623 school- and university students, only three complaints have been received about unfair judgement by peers. This can be interpreted as yet another measure of its autonomy-supportive quality.

\section{Signs from literature that the quality of motivation may affect team effectiveness}

Numerous studies on team effectiveness deal with procedure-oriented interventions: how to enforce specific teamwork skills and behavioral engagement. These are primarily about goal-oriented issues such as group reflexivity and after-action reviews (collectively referred to as feedback) (Kluger \& DeNisi 1996; Smither et al 2005, London \& Mone, 2015). Group reactive planning (Marks, et al., 2001), an essential determinant of group effectiveness (DeChurch \& Haas, 2008), depends on how procedure-oriented interventions are processed by group members (Smither et al., 
2005). This processing seems to be determined by at least two personality traits; the first concerns goal orientation and the second perception of autonomy. Smither et al. (2005) observed a wide variation in the way individuals process feedback. To explain this, they proposed that feedback works best for recipients with high self-efficacy and a "learning" goal-orientation. Learning goal-orientation includes goals related to a mastery approach; eager to learn for personal development and to make the group work better (Deci et al., 1981; Chapter 9, p216, Ryan \& Deci, 2017; described in "Relationship Motivation Mini-Theory" of Self-Determination Theory, Chapter 12, p293, Ryan \& Deci, 2017; Vansteenkiste et al., 2004). Feedback works less for recipients who focus on managing others' impressions of them (Smither et al., 2005). In this case, we are dealing with performance goalorientation (VanSteenkiste et al., 2004). The second personality trait associated with a positive effect of feedback is that the recipient has a sense of control over the desired improvement (Maurer \& Palmer, 1999). The sense of control depends on the context, what choices are given to group members. It follows that group reactivity is likely to be greater in autonomy-supportive contexts associated with mastery goal-orientation. These motivational constructs link the quality of motivation to group effectiveness.

\section{Limitations and Issues for Future Research}

The study has shortcomings, both with respect to the control of independent variables and the number of students involved. For instance, there remains the possibility that the higher scores of the IMI can be explained by a non-random selection of the student populations (control versus experimental). It is possible that the experimental classes consisted of more self-determined and academically more capable students. We have two arguments against these possibilities: firstly, the chance of repeatedly selecting biased populations over a period 4 years must be rather small, and secondly, the overall control and experimental population for the years 2016 to 2018 had similar semester grades. The observed effects could also be explained by the novelty of the intervention. Moreover, the students receive more attention from the teacher in the experimental classes and this, as a form of reward, may lead to a more favorable evaluation of the group project. Indeed, during the interventions at schools, some students express their gratitude that a university teacher is participating in their school project. This gratitude was expressed both in control and experimental classes. The question is what "meaningful” alternative activity can you apply in the 
control classes that should have no effect on the internalization of motivation? Suggestions are welcome. Also, we studied the self-evaluation procedure in a single academic environment, students at secondary schools. Moreover, we did not study how exactly the procedure changes the constructive transactive dialogue. We also were not in the position to measure the impact on group performance because we could not assist in the grading of the projects of our classes and we therefore could not verify the grading arguments. In any case, objectively measuring group performance can be difficult with complex tasks such as open-ended projects, with a wide range of subjects and multiple possible approaches. We are currently assessing to what extent students appreciate fairness of assessment and to what extent the self-evaluation contributes to this fairness. We also seek to study whether or not group self-evaluation had changed students' group beliefs.

\section{Data availability statement:}

The data that support the findings of this study are available from the corresponding author upon reasonable request.

\section{Acknowledgements:}

This project was developed in collaboration with the Rectorat de l'Academie de Bordeaux as part of an exchange project between secondary- and higher-education institutions, with the mission to find ways to smoothen the transition between the two. Bruno Forestier, Rectorat de l'Académie de Bordeaux and Sophie Canteloube-Fronty, now at the Rectorat de l'Académie d'Orléans-Tours, are acknowledged for their interest in- and continuous support of this research project. We thank Marlène Cachet, Collège Elisée Mousnier, Cognac, France, for her help with the translation and adaptation of the IMI to the TPE project. We thank Dr Hermelijn Smith and Dr Bart Everts, University of Leiden Medical School, the Netherlands, for employing the group selfevaluation procedure in a science-writing blog project of a Master course and sharing their experiences with us. The web-based self-evaluation tool was developed in collaboration with Willem van der Velden. We thank Dr Anneke Kramer, Leiden University Medical Center, the Netherlands, for critical reading of the manuscript. 


\section{Conflict of interest (COI)}

The authors declare no conflict of interest.

\section{References}

Adler, P., Heckscher, C., \& Prusak, L. (2011). Building a collaborative enterprise. Harvard Business Review, issue July-August. (http://faculty.marshall.usc.edu/PaulAdler/research/HBR_Building_collaborative.pdf)

Aggarwal, P., \& O’Brien. (2008). Social loafing on group projects: structural antecedents and effect on student satisfaction. Journal of Marketing Education, 30(3), 255-264.

American Psychology Association. (2020). Publication Manual of the American Psychological Association ( $7^{\text {th }}$ ed.). https://doi.org/10.1037/00000165-000

Archer-Kath, J., Johnson, D.W., \& Johnson, R.T. (1994). Individual versus group feedback in cooperative groups. The Journal of Social Psychology 134(5), 681-694. https://doi.org/10.1080/00224545.1994.9922999

Asgari, S., \& Dall'Alba, G. (2011). Improving Group Functioning in Solving Realistic Problems. International Journal for the Scholarship of Teaching and Learning, 5(1), Article 8. http://digitalcommons.georgiasouthern.edu/ij-sotl/vol5/iss1/8

Barab, S. A., Squire, K. D., \& Dueber, W. (2000). A co-evolutionary model for the supporting the emergence of authenticity. Educational Technology Research and Development, 48(2), 37-62. https://doi.org/10.1007/BF02313484

Baumeister, R., \& Leary, M.R. (1995). The need to belong: desire for interpersonal attachments as a fundamental human motivation. Psychological Bulletin, 117, 497-529. 
Beaton, D. E., Bombardier, C., Guillemin, F., \& Ferraz, M. B. (2000). Guidelines for the process of crosscultural adaptation of self-report measures. Spine, 25(24), 3186-3191.

Blatchford, P., Baines, E., Rubie-Davies, C., Bassett, P., \& Chowne A. (2006). The effect of a new approach to group work on pupil-pupil and teacher-pupil interactions. Journal of Educational Psychology, 98(4), 750-765. https://doi.org/10.1037/0022-0663.98.4.750

Blatchford, P., Kutnick, P., Baines, E., \& Galton, M. (2003). Toward a social pedagogy of classroom group work. International Journal of Educational Research, 39(1/2), 153-172. https://doi.org/10.1016/S0883-0355(03)00078-8

Blumenfeld, P. C., Soloway, E., Marx, R. W., Krajcik, J. S., Guzdial, M., \& Palincsar, A. (1991). Motivating project-based learning: Sustaining the doing, supporting the learning. Educational Psychologist, 26(3/4), 369-398. https://doi.org/10.1080/00461520.1991.9653139

Brown, R.W. (1995, November 1-4). Autorating: Getting individual marks from team marks and enhancing teamwork. Proceedings Frontiers in Education, $25^{\text {th }}$ Annual Conference, Atlanta, GA, USA. https://doi.org/10.1109/FIE.1995.483140

Chang, Y., \& Brickman, P. (2018). When group work doesn’t work: insights from students? CBE-Life Sciences Education, 17(ar52), 1-17. https://doi.org/10.1187/cbe.17-09-0199

Chapman, K.J., \& van Auken, S. (2001). Creating positive group project experiences: an examination of the role of the instructor on student's perception of group projects. Journal of Marketing Education 23(2), 117-127. https://doi.org/10.1177/0273475301232005

Cheng, W., \& Warren, M. (2000). Making a difference: using peers to assess individual students' contributions to a group project. Teaching in Higher Education 5(2), 243-255. https://doi.org/10.1080/135625100114885

Conway, R., Kember, D., \& Wu, A.S \& M. (1993). Peer assessment of an individual's contribution to a group project. Assessment \& Evaluation in Higher Education, 18(1), 45-56. https://doi.org/10.1080/0260293930180104 
De Charms, R. (1968). Personal causation: the internal affective determinants of behavior. Routledge. ISBN 0-89859-336-0

DeChurch, L.A. \& Haas, C.D. (2008). Examining team planning through an episodic lens effects of deliberate, contingency, and reactive planning on team effectiveness. Small Group Research, 39, 542-568. https://doi.org/10.1177/1046496408320048

Deci, E. L., Eghrari, H., Patrick, B. C., \& Leone, D. R. (1994). Facilitating internalization: The selfdetermination perspective. Journal of Personality, 62, 119-142. https://doi.org/10.1111/j.14676494.1994.tb00797.x

Deci, E.L., \& Ryan, R.M. (1980). The empirical exploration of intrinsic motivational processes. In L. Berkowitz (Ed). Advances in experimental social psychology (Vol.13, pp. 39-80). Academic Press.

Deci E.L., \& Ryan, R.M. (1985). The general causality orientations scale: Self-determination in personality. Journal of Research in Personality, 19(2), 109-134. https://selfdeterminationtheory.org/SDT/documents/1985_DeciRyan_GCOS.pdf

Deci, E.L., Schwartz, A., Sheinman, L., \& Ryan, R.M. (1981). An instrument to assess adult's orientation toward control versus autonomy in children: reflections on intrinsic motivation and perceived competence. Journal of Educational Psychology, 73, 642-650. https://doi.org/10.1037/0022$\underline{0663.73 .5 .642}$

Eddy, E. R., Tannenbaum, S. I., \& Mathieu, J. E. (2013). Helping teams to help themselves: Comparing two team-led debriefing methods. Personnel Psychology, 66, 975-1008). https://doi.org/10.1111/peps.12041

Dijkstra, J., Latijnhowers, M., Norbart, A. \& Tio, R.A. (2016). Assessing the "I" in group work assessment: state of the art and recommendations for practice. Medical Teacher 38(7), 675-682. https://doi.org/10.3109/0142159X.2016.1170796

Domen, J., Hornstra, L., Weijers, D., van der Veen, I., \& Peetsma, T. (2019). Differentiated need support by teachers: student-specific provision of autonomly and structure and relations with student 
motivation. Britisch Journal of Educational Psychology, 90(2), 403-423.

https://doi.org/10.1111/bjep.12302

Forsell, J., Forslund Frykedal, K., \& Hammar Chiriac, E. (2020). Group Work Assessment: Assessing Social Skills at Group Level. Small Group Research, 51(1), 87-124. https://doi.org/10.1177/1046496419878269)

Freeman, M., \& McKenzie, J. (2002). SPARK, a confidential web-based template for self and peer assessment of student teamwork: benefits of evaluating across different subjects. British Journal of Educational Technology, 33: 551-569. https://doi.org/10.1111/1467-8535.00291

Gabelica, C., Van den Bossche P., Segers, M., \& Gijselaers, W. (2012). Feedback, a Powerful Lever in Teams: A Review. Educational Research Review, 7 (2), 123-144. https://doi.org/10.1016/j.edurev.2011.11.003

Garrison, D.R., \& Akyol, Z. (2015). Toward the development of a metacognition construct for communities of inquiry. The Internet and Higher Education, 24, 66-71. https://doi.org/10.1016/j.iheduc.2014.10.001

Gillies, R.M. (2004). Structuring cooperative group work in classrooms. International Journal of Educational Research 39(1,2), 35-49. https://doi.org/10.1016/S0883-0355(03)00072-7

Goldfinch, J. (1994). Further developments in peer-assessment of group projects. Assessment and Evaluation in Higher Education 19(1), 29-35. https://doi.org/10.1080/0260293940190103

Hackman, J.R., \& Morris, C.G. (1975). Group tasks, group interaction process, and group performance effectiveness: a review and proposed integration. Advances in Experimental Social Psychology, 8, 45-99. https://doi.org/10.1016/S0065-2601(08)60248-8

Harkins, S.G., \& Petty, R.E. (1982). Effects of task difficulty and task uniqueness on social loafing. Journal of Personality and Social Psychology, 43(6), 1214-1229. https://doi.org/10.1037/00223514.43.6.1214 
Harris, M.J. \& Rosenthal, R. (1985). Mediation of interpersonal expectancy effects: 31 meta-analyses. Psychological Bulletin, 97, 363-386. https://doi.org/10.1037/0033-2909.97.3.363

Hoever, I.J., van Knippenberg, D., van Ginkel, W.P., \& Barkema, H.G. (2012). Fostering team creativity: perspective taking as key to unlocking diversity’s potential. Journal of Applied Psychology, 97(5), 582-996. https://doi.org/10.1037/a0029159

Hollenbeck, J.R., Beersma, B., \& Schouten, M.E. (2012). Beyond team types and taxonomies: a dimensional scaling conceptualization for team description. Academy of Management Review, 37(1), 82-106.

Johnson, D.W., \& Johnson, R.T. (2009). An educational psychology success story: social interdependence and cooperative learning. Educational Researcher, 38(5), 365-379). https://doi.org/10.3102/0013189X09339057

Johnson, D.W., Johnson, R.T., \& Smith, K.A. (1998). Cooperative learning returns to college: what evidence is there that it works? Change: The Magazine of Higher Learning, 30(4), 27-35. https://doi.org/10.1080/00091389809602629

Kao, G.Y.-M. (2013). Enhancing the quality of peer review by reducing student “free riding”: Peer assessment with positive interdependence. British Journal of Educational Technology, 44, 112124. https://doi.org/10.1111/j.1467-8535.2011.01278.x

Karau, S.J., \& Williams, K.D. (1993). Social loafing: a meta-analytic review and theoretical integration Journal of Personality and Social Psychology, 65(4), 681-706.

Kench, P. L., Field, N., Agudera, M., \& M. Gill. (2009). Peer Assessment of Individual Contributions to a Group Project: Student Perceptions. Radiography, 15(2), 158-165. https://doi.org/10.1016/j.radi.2008.04.004 
Ko, S.-S. (2013). Peer assessment in group projects accounting for assessor reliability by an iterative method. Teaching in Higher Education, 19, 301-314. https://doi.org/10.1080/13562517.2013.860110

Kilic, G.B., Cakan, M. (2006). The analysis of the impact of individual weighting factor on individual scores. Assessment \& Evaluation in Higher Education, 31(5), 639-654. https://doi.org/10.1080/02602930600760843

Kaufman, D.B., Felder, R.M., \& Fuller, H. (2013). Accounting for individual effort in cooperative learning teams. Journal of Engineering Education, 89(2), 133-140. https://doi.org/10.1002/j.21689830.2000.tb00507.x

Kramer, I.M., \& Kusurkar, R.A. (2017). Science-writing in the blogosphere as a tool to promote autonomous motivation in education. The Internet and Higher Education, 35, 48-62. https://doi.org/10.1016/j.iheduc.2017.08.001

Kusurkar, R.A, Croiset, G., \& Ten Cate, T.J. (2011). Twelve tips to stimulate intrinsic motivation in students through autonomy-supportive classroom teaching derived from self-determination theory. Medical Teacher, 33, 978-982. https://doi.org/10.3109/0142159X.2011.599896

Kusurkar, R.A., \& Croiset, G. (2015). Autonomy support for autonomous motivation in medical education. Medical Education Online, 20, 27951. https://doi.org/10.3402/meo.v20.27951

Langsrud, O. (2003). ANOVA for unbalanced data: Use Type II instead of Type III. Statistics and Computing, 13(2), 163-167. https://doi.org/10.1023/A:1023260610025

Larmer, J., \& Mergendoller, J. R. (2010). Seven essentials for project-based learning. Educational Leadership, 68(1), 34-37. http://www.ascd.org/publications/educational_leadership/sept10/vol68/num01/Seven_Essentials_f or_Project-Based_Learning.aspx 
Lejk, M., \& M. Wyvill. (2001a). Peer Assessment of Contributions to a Group Project: A Comparison of Holistic and Category-based Approaches. Assessment \& Evaluation in Higher Education, 26(1), 61-72). https://doi.org/10.1080/02602930020022291

Lejk, M., \& M. Wyvill. (2001b). The effect of the Inclusion of Self-assessment with Peer Assessment of Contributions to a Group Project: A Quantitative Study of Secret and Agreed Assessments. Assessment \& Evaluation in Higher Education, 26(6), 551-561. https://doi.org/10.1080/02602930120093887

Marks, M.A., Mathieu, J.E., \& Zaccaro, S.J. (2001). A temporally based framework and taxonomy of team processes. Academy of Management Review, 26(3), 356-376. https://doi.org/10.5465/amr.2001.4845785

Maurer TJ, \& Palmer JK. (1999). Management development intentions following feedback: Role of perceived outcomes, social pressures, and control. Journal of Management Development, 18, 733751. https://doi.org/10.1108/02621719910300784

McAuley, E., Duncan, T., \& Tammen, V. V. (1989). Psychometric properties of the intrinsic motivation inventory in a competitive sport setting: A confirmatory factor analysis. Research Quarterly for Exercise and Sport, 60(1), 48-58. https://doi.org/10.1080/02701367.1989.10607413

Mello, J. A. (1993). Improving Individual Member Accountability in Small Work Group Settings. Journal of Management Education, 17, 253-259. doi/pdf/10.1177/105256299301700210

Mesch, D. J. (1991). The jigsaw technique/ a way to establish individual accountability in group work. Journal of Management Education, 15(3), 355-358. https://doi.org/10.1177/105256299101500308

Neus, J. L. (2011). Peer Assessment Accounting for Student Agreement. Assessment \& Evaluation in Higher Education, 36(3); 301-314. https://doi.org/10.1080/02602930903342315

O'Neill, T.A., Deacon, A., Gibbard, K., Larson, N., Hoffart, G., Smith, J., \& Donia, B.L.M. (2018). Team dynamics feedback for postsecondary student learning teams, Assessment \& Evaluation in Higher Education, 43(4), 571-585. https://doi.org/10.1080/02602938.2017.1380161 
R Core Team. (2018). R: A language and environment for statistical computing. R Foundation for Statistical Computing, Vienna, Austria. ISBN 3-900051-07-0. http://www.R-project.org/

Reeve. J, \& Jang, H. (2006). What teachers say and do to support students' autonomy during a learning activity. Journal of Educational Psychology, 98(1), 209-218. https://doi.org/10.1037/0022$\underline{0663.98 .1 .209}$

Reis, H.T. (1994). Domains of experience: investigating relationship processes from three perspectives. In R. Erber, \& R. Gilmour (Eds.), Theoretical frameworks for personal relationships (pp. 87-110). Psychology Press. eBook ISBN 9780203772065

Ryan, R. (1982). Control and information in the intrapersonal sphere an extension of cognitive evaluation theory. Journal of Personality and Social Psychology, 43, 450-461. https://doi.org/10.1037/0022$\underline{3514.43 .3 .450}$

Ryan, R.M. (1995). Psychological needs and the facilitation of integrative processes. Journal of Personality, 63, 397-427. https://doi.org/10.1111/j.1467-6494.1995.tb00501.x

Ryan, R.M., \& Deci, E.L. (2000a). Self-determination theory and the facilitation of intrinsic motivation, social development, and well-being. American Psychologist, 55, 68-78. https://psycnet.apa.org/buy/2000-13324-007

Ryan, R.M., Deci, E.L. (2000b). Intrinsic and extrinsic motivations: classic definitions and new directions. Contemporary Educational Psychology, 25, 54-67. https://doi.org/10.1006/ceps.1999.1020

Ryan, R.M., \& Deci, E.L. (2017). Self-determination theory: basic psychological needs in motivation, development, and wellness. The Guilford Press. ISBN 9781462528769. https://doi.org/10.1521/978.14625/28806

Salas, E., DiazGranados, D., Klein, C., Burke, C.S., \& Stagl, K.C. (2008). Does team training improve team performance? A meta-analysis. Human Factors 50(6), 903-933. https://doi.org/10.1518/001872008X375009 
Scager, K., Boonstra, J., Peeters, T., Vulperhorst, J., \& Wiegant, F. (2016). Collaborative learning in higher education: Evoking positive interdependence. CBE-Life Sciences Education, 15(ar69), 1-9. https://doi.org/10.1187/cbe.16-07-0219

Slavin, R.E. (1996). Research on cooperative learning and achievement: What we know, what we need to know. Contemporary Educational Psychology, 21, 43-69. https://doi.org/10.1006/ceps.1996.0004

Smither, J. W., London, M., \& Reilly, R. R. (2005). Does performance improve following multisource feedback? A theoretical model, meta-analysis, and review of empirical findings. Personnel Psychology, 58, 33-66. https://doi.org/10.1111/j.1744-6570.2005.514_1.x

SPARKplus (n.d.). https://sparkplus.com.au/

Spatar, C., Penna, N., Mills, H., Kutija, V., \& Cooke, M. (2014). A robust approach for mapping group marks to individual marks using peer assessment. Assessment \& Evaluation in Higher Education, 40(3), 371-389. https://doi/10.1080/02602938.2014.917270

Sridharan, B., Tai, J., \& Boud, D. (2019). Does the use of summative peer assessment in collaborative group work inhibit good judgement? Higher Education, 77(5), 853-870. https://doi.org/10.1007/s10734-018-0305-7

Stangroom, J. (2018). Effect size calculator. https://www.socscistatistics.com/effectsize/default3.aspx

Strong, J.T., \& Anderson, R.E. (1990). Free-riding in group projects: control mechanisms and preliminary data. Journal of Marketing Education, 12(2), 61-67. https://doi.org/10.1177/027347539001200208

Tolmie, A.K., Topping, K.J., Christie, D., Donaldson, C., Howe, C., Jessiman, E., Linvingston, K., \& Thurston, A. (2010). Social effects of collaborative learning in primary schools. Learning and Instruction, 20(3), 177-191. https://doi.org/10.1016/j.learninstruc.2009.01.005 
Tuckman, B., \& Jensen, M.A.C. (1977). Stages of small-group development revisited. Group \& Organization Studies, 2(4), 419-427. https://doi.org/10.1177/105960117700200404

Van den Bossche, P., Gijselaers, W.H., Segers, M., \& Kirschner P.A. (2006). Social and cognitive factors driving teamwork in collaborative learning environments. Team learning beliefs \& behaviors. Small Group Research, 37(5), 490-521. https://doi.org/10.1177/1046496406292938

Vansteenkiste, M., Simons, J, Lens, W., Sheldon, K.M., \& Deci, E.L. (2004). Motivating learning, performance, and persistence: the synergistic effects of intrinsic goal contents and autonomysupportive contexts. Journal of Personality and Social Psychology, 87(2), 246-260. https://doi.org/10.1037/0022-3514.87.2.246

Visser, C. L. F., Ket, J. C. F., Croiset, G., \& Kusurkar, R. A. (2017). Perceptions of residents, medical and nursing students about Interprofessional Education; a systemic review of the quantitative and qualitative literature. BMC Medical Education, 17, 77. https://doi.org/10.1186/s12909-017-0909-0

Weaver, D., \& Esposto, A. (2012). Peer Assessment as a Method of Improving Student Engagement. Assessment \& Evaluation in Higher Education, 37(7), 805-816. https://doi.org/10.1080/02602938.2011.576309

White, R.W. (1959). Motivation reconsidered: The concept of competence. Psychological Review, 66(5), 297-333. https://doi.org/10.1037/h0040934

Williams, K., Harkins, S.G., \& Latané, B. (1981). Identifiability as a deterrent to social loafing: two cheering experiments. Journal of Personality and social Psychology 40(2), 303-311. https://doi.org/10.1037/0022-3514.40.2.303

Zimmerman, B.J. (1990). Self-regulated learning and academic achievement: an overview. Educational Psychologist, 25, 3-17. https://doi.org/10.1207/s15326985ep2501_2

Zimmerman, B.J. (2008). Investigating self-regulation and motivation: Historical background, methodological developments and future prospects. American Educational Journal, 45, 166-183. https://doi.org/10.3102/000283120731290 


\section{Online Supplementary Material}

Manuscript: “Group Self-Evaluation Primes for Autonomous Motivation in Collaborative Learning”

Figure S1. A taxonomy of human motivation of Self-Determination Theory.

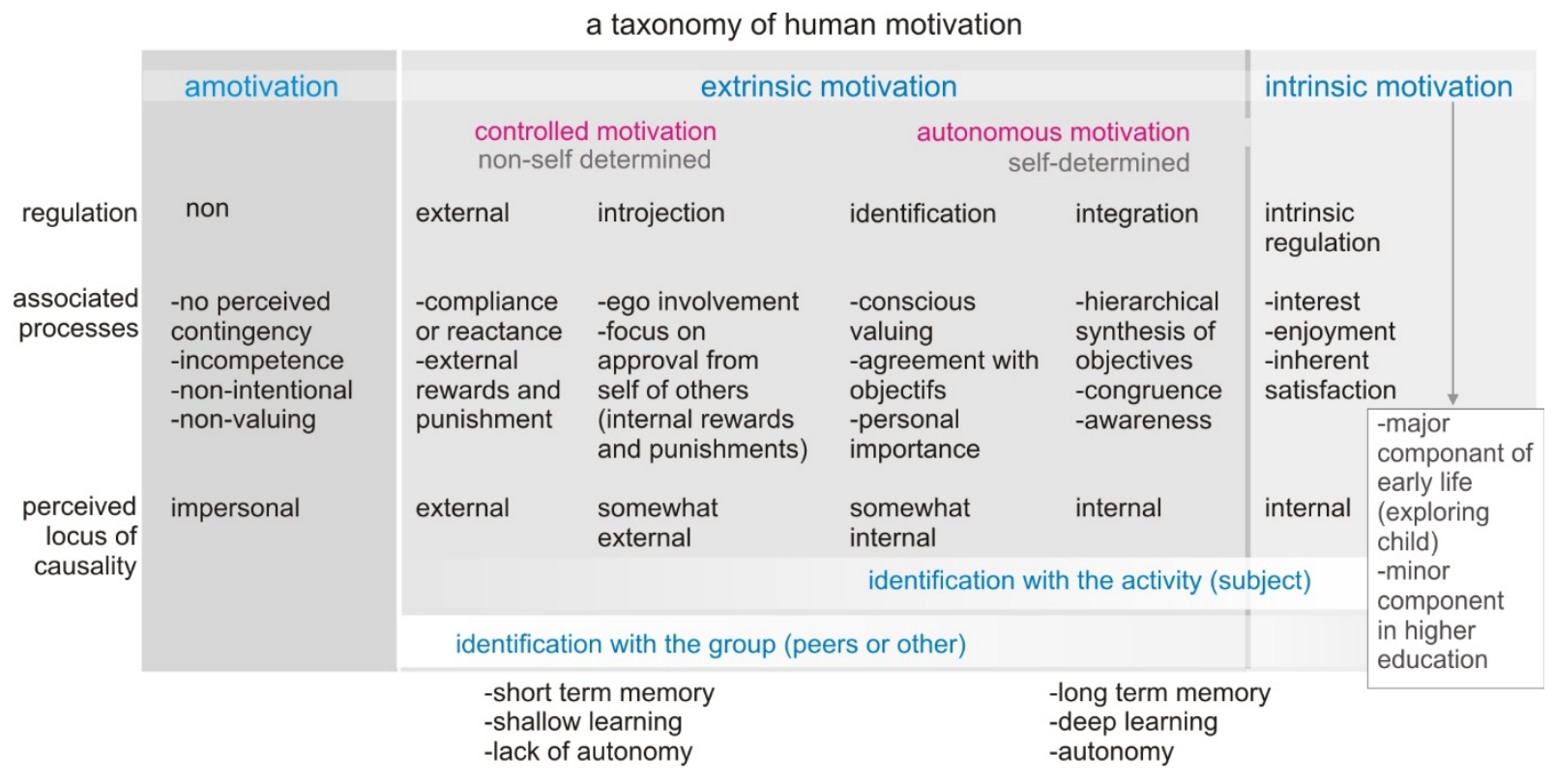

self determination theory of Ryan RM \& Deci EL

Figure caption: Self Determination Theory distinguishes between behavior that is motivated by autonomous reasons and controlled reasons. Three qualities of motivation are identified (from right to left): 1) intrinsic, 2) extrinsic and 3) amotivation (Ryan \& Deci, 2000a, 2000b). Intrinsic motivation occurs when an activity has inherent satisfaction, it offers enjoyment and it is interesting in its own right. The enjoyment procures vitality and people can sustain such activities for a long time. Extrinsic motivation comes in two forms: behavior driven by autonomous motivation, also known as self-determined, or behavior driven by controlled motivation. In the case of autonomous motivation, the activity as such is not necessarily enjoyable, but it has full personal endorsement or the goal has a strong personal value. The activity fits in a long term plan such as preparing for a job or maintaining good health. The internalization of regulation can occur at the level of integration of values and objectives, which means that what you are actually doing and what you would like to do are fully integrated, or at the level of identification, where there is agreement but not more. Controlled motivation pertains 
to feeling pressured to behave in a certain way or to pursue a certain goal. In the case of introjection, the pressure comes from within, a matter of ego-involvement, living up to a certain image of oneself, like keeping up the reputation of being smart or beautiful. External regulation refers to the engagement in an activity or pursuing goals in order to meet external demands such as pressure from the family, superiors or peers. In the case of amotivation, there is no regulation, the person does not feel concerned, he/she has no relation with the activity. Boredom in class may be a manifestation of amotivation. Controlled regulation means that participation in an activity will cease as soon as the pressure drops, for instance when the teacher has gone or the peers are no longer watching. This is not the case with autonomously regulated behavior, the activity continues until the task or the objective is reasonably achieved. Numerous studies have revealed that autonomous regulation is associated with concentration, persistence, good time management, and deep learning. In contrast, controlled motivation predicted outcomes such as maladaptive coping strategies, test anxiety, superficial learning, and school dropout. These results have been obtained across age groups (i.e., from elementary to high school) and across cultures (Ryan \& Connell, 1989; Ryan \& Deci, 2017). With respect to vitality, autonomously motivated behavior in pursuit of intrinsic goals (self-acceptance, working for the community, personal growth) is associated with satisfaction of three psychological needs, namely a sense of autonomy (agency), competence (feeling capable) and relatedness (belonging to a social community). In controlled motivation, there is a tendency to sacrifice any of these needs for the sake of a career, a celebrity status or other extrinsic goals (goals of action that extend beyond those inherent in the activity itself). The neglect of psychological needs, in the pursuit of extrinsic goals, is emotionally expensive.

Intrinsic and autonomous motivation are associated with an internal perceived locus of causality. What this means is that, for a specific task or challenge, people see choices, identify opportunities for self-control and take initiatives to bring the activity to a good end. These people approach the task with an autonomous causality-orientation (Deci \& Ryan, 1985; causality minitheory, Chapter 9, Ryan \& Deci, 2017). Extrinsic motivation is associated with an external perceived locus of causality. Here people approach the task or challenge with a controlled causality-orientation and they predominantly see restrictions in the activity, they focus on external control and often provide just enough effort to come out unscathed. In the context of collaborative projects, social loafers may fit into this category (Aggarwal \& O’Brien, 2008). In 
the case of amotivation, the locus of causality is impersonal. Impersonal causality-orientation means that members fully orient toward obstacles to goal attainment, seek no affinity with the task and feel no control over the outcome. From a collaborative project perspective, free riders may fit into this category. Importantly, none of these features are fixed personality traits, motivations and orientations may change from activity to activity, they are situation-dependent (Vallerand, 1997).

\section{References}

- Aggarwal, P., \& O’Brien. (2008). Social loafing on group projects: structural antecedents and effect on student satisfaction. Journal of Marketing Education, 30(3), 255-264.

-Deci E.L., \& Ryan, R.M. (1985). The general causality orientations scale: Self-determination in personality. Journal of Research in Personality, 19(2), 109-134.

-Ryan, R. M., \& Connell, J. P. (1989). Perceived locus of causality and internalization: Examining reasons for acting in two domains. Journal of Personality and Social Psychology, 57, 749-761.

-Ryan RM, Deci EL. (2000a). Self-determination theory and the facilitation of intrinsic motivation, social development, and well-being. American Psychologist 55, 68-78

-Ryan RM, Deci EL. (2000b). Intrinsic and extrinsic motivations: classic definitions and new directions. Contemporary Educational Psychology 25, 54-67

-Ryan, R.M., \& Deci, E.L. (2017). Self-determination theory: basic psychological needs in motivation, development, and wellness. Ryan \& Deci (Eds). New York: Guilford Press. ISBN 9781462538966.

-Vallerand, R. J. (1997). Toward a hierarchical model of intrinsic and extrinsic motivation. In M. P. Zanna (Ed.), Advances in experimental social psychology (pp. 271-360). New York: Academic Press. 


\title{
Online Supplemental Material
}

Manuscript: “Group Self-Evaluation Primes for Autonomous Motivation in Collaborative Learning”

\section{Figures S2 : collaborative learning $\&$ group working}

\author{
IJsbrand KRAMER \\ IECB-INSERM 1026 \\ Université de Bordeaux \\ ijsbrandkramer@gmail.com \\ http://www.cellbiol.net
}


- defining the task

- making a plan

- allocation work \& resources

- controlling quality \& tempo of work

- checking performance against plan

- adjusting plan

\section{Challenges for collaborative projects}

\section{- setting standards}

\section{individual needs}

\section{build a} team

- maintaining discipline

- building team spirit

- provide sense of purpose

- appointing roles

- ensuring communication within team 


\section{Different personalities, different roles within the team}

\section{different personnalities, different roles within the team}

thinker type

- I have to work things out first

action person

I have to get on with things

- I am introvert and prefer to work alone first before I act in the team

I am extrovert

- I am not a very good communicator

I may seem bossy

social or people person

- I am aware of how and sensitive to peoples behaviour in the team

- I enjoy being part of team

- I take pleasure in communication with the team

reflect on the role that would suit you best in the team, taking into account your personality traits 


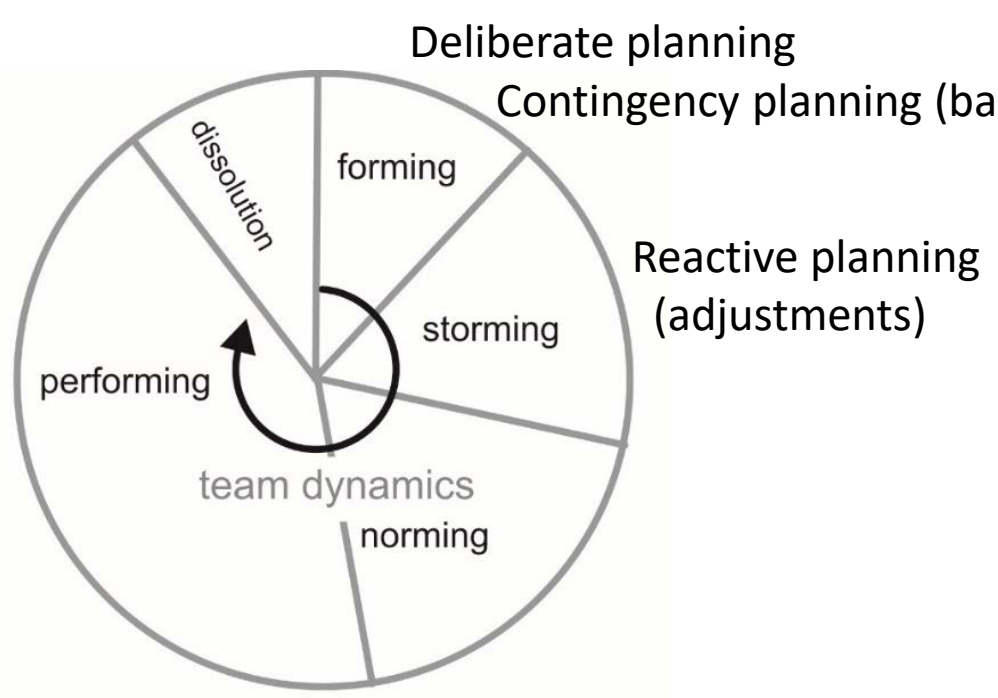

\section{Team development stages}

Forming: group membership, which orientation to choose for the task, individual pursuit of knowledge ("information foraging"), deliberate planning and contingency planning Storming: gathering knowledge for co-construction (sharing) and new delegation of tasks: possible source of dispute, mistrust and emotional reaction to the demands of the task, reactive planning (adjustments, most important element of team effectiveness) Norming: Establish constructive dialogue ("constructive conflict"), build trust, reconsider team rules and culture, strengthen cohesion.

Performing: trust grows, the team works to get the job done.

The duration and intensity of the different phases vary between teams and tasks.

Adapted from Tuckman B. (1965). Developmental sequence in small groups. Psych Bull 6,384-399. Bossche et al (2006). Social and cognitive factors driving teamwork in collaborative learning environments. Small Group Research 37(5), 490-521; DeChurch \& Haas. (2008). Examining team planning through an episodic lens. Effects of deliberate, contingency, and reactive planning on team effectiveness. Small Group Research, 39(5), 542-568. 


\section{An effective group-led debrief approach should include the following five features}

1. allow group members to reflect independently and anonymously (for psychological safety and to avoid being influenced by the most vocal team member)

2. ensure all group members provide input to enhance their sense of ownership and capture all perspectives;

3. focus attention on group work and not just taskwork, because teamwork also drives team effectiveness and groups tend not to discuss it;

4. guide the group to discuss divergent or high priority needs early in the debrief and not simply areas of agreement or comfortable topics

5. lead the group to the formation of future-looking action plans and agreements (reactive planning). 


\section{the group self-evaluation procedure}

- At the start of the course:

Define the ground rules (the rules of operation for the team).

- Midway through the course:

a) interview with the teacher to check the progress of the project

b) self-evaluation of the team's functioning (to what extent do the members respect the rules of conduct)

- At the end of the project:

a) self-evaluation of the team's functioning

b) complete a motivation survey (IMI). 


\section{example of a self-assessment page (mid-term and final)}

\section{The group leiden colorectal \\ The member colorectal end of course for}

student completed the assigned task in time (respect deadlines)

student listened to the opinions of others

Seven ground rules set by the group
Does he/she adhere to the proposed rules of conduct \begin{tabular}{|l|l|l|}
\hline Disappointing & Moderate & Excellent \\
\hline
\end{tabular} \begin{tabular}{|l|l|l}
\hline Disappointing & Moderate & Excellent \\
\hline
\end{tabular} student joined the discussion (in sessions/on web)

student provided constructive criticism

student assured an equal distribution of tasks

student assisted others with difficult tasks

student informed the team about difficulties with his/her tasks

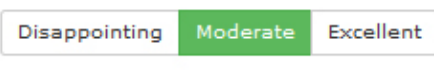

Disappointing Moderate Excellent Disappointing Moderate Excellent Disappointing Moderate Excellent Disappointing Moderate Excellent -return to previous page -data are kept but can still be modified -data are saved -if you made an error you must ask the instructor by email to reset your entry 
Instruction to students at the start of the project

To function well as a group, you will define your own ground rules (rules of functioning of the group), a minimum of 5 and a maximum of 7 


\begin{tabular}{|l|l|l|}
\hline \multicolumn{2}{|l|}{ Nom de l'équipe/thème de projet: } \\
\hline Membres & $\begin{array}{l}\text { Nom mettez les noms en ordre } \\
\text { alphabétique du nom de famille }\end{array}$ & prénom \\
\hline 1 & & \\
\hline 2 & & \\
\hline 3 & & \\
\hline 4 & & \\
\hline 5 & \multicolumn{1}{|c|}{ These are examples ! } \\
\hline Activité A "établir les règles de base " \\
Remplir collectivement, au début du projet
\end{tabular}


Table S1. Mid-term progress report

\begin{tabular}{|c|c|c|}
\hline Name of the team : & & \\
\hline Mid-term progress report (to be filled out by accompanying teacher) & YES & NO \\
\hline \multicolumn{3}{|l|}{1 Do you have a problematic i.e. what is the question that you are going to work on? } \\
\hline Title of the project: & $\mathbf{0}$ & $\mathbf{0}$ \\
\hline \multicolumn{3}{|l|}{2 Do you have a project plan? } \\
\hline List the project plan: & $\mathbf{O}$ & $\mathbf{0}$ \\
\hline \multicolumn{3}{|c|}{$\begin{array}{l}3 \text { Do you have written documents of the plan and has this document been consulted by all group } \\
\text { members? }\end{array}$} \\
\hline Proof of written document: & $\mathbf{0}$ & $\mathbf{0}$ \\
\hline \multicolumn{3}{|l|}{4 is there a task delegation and, if so, who takes care of what? } \\
\hline If yes, what is the task delegation (task per group member) : & $\mathbf{O}$ & $\mathbf{0}$ \\
\hline \multicolumn{3}{|l|}{5 Is your project bi-disciplinary, which other discipline is involved besides biology? } \\
\hline Describe the second discipline: & $\mathbf{0}$ & $\mathbf{0}$ \\
\hline \multicolumn{3}{|l|}{6 Has the group contacted experts inside or outside the school? } \\
\hline $\begin{array}{l}\text {-Name(s) of school teacher(s) you have contacted with expert knowledge on the } \\
\text { subject proposed: } \\
\text {-Name(s) of external experts you have contacted (University laboratories, companies } \\
\text { or learned societies: }\end{array}$ & 0 & 0 \\
\hline \multicolumn{3}{|l|}{7 What kind of documents have you consulted for your research? } \\
\hline Write down examples of books, multimedia resources or other: & $\mathbf{0}$ & $\mathbf{0}$ \\
\hline \multicolumn{3}{|l|}{ Optional: have you thought of an experiment for your project } \\
\hline \multicolumn{3}{|l|}{ Description of proposed experiment: } \\
\hline Count the number of YES circles ticked & & Syes \\
\hline To be filled in by the students & YES & NO \\
\hline $\begin{array}{l}\text { Do you have the impression that all groups in the class receive equal attention from } \\
\text { the accompanying teachers? }\end{array}$ & 0 & $\mathbf{0}$ \\
\hline $\begin{array}{l}\text { Does your group get enough attention and support from the accompanying } \\
\text { teachers? }\end{array}$ & $\mathbf{0}$ & $\mathbf{0}$ \\
\hline Do you have any comments or suggestions? & & \\
\hline
\end{tabular}


Table S2. IMI school project

The questions are regrouped by subscale for the sole purpose of giving insight in how quantitative data were obtained for each subscale. Questions with (R) are calculated as 8 minus the box number ticked. Questions are presented to students in the order of $1,8,14,19,24,31,2$, 9, etc. An example of calculation is shown below the table.

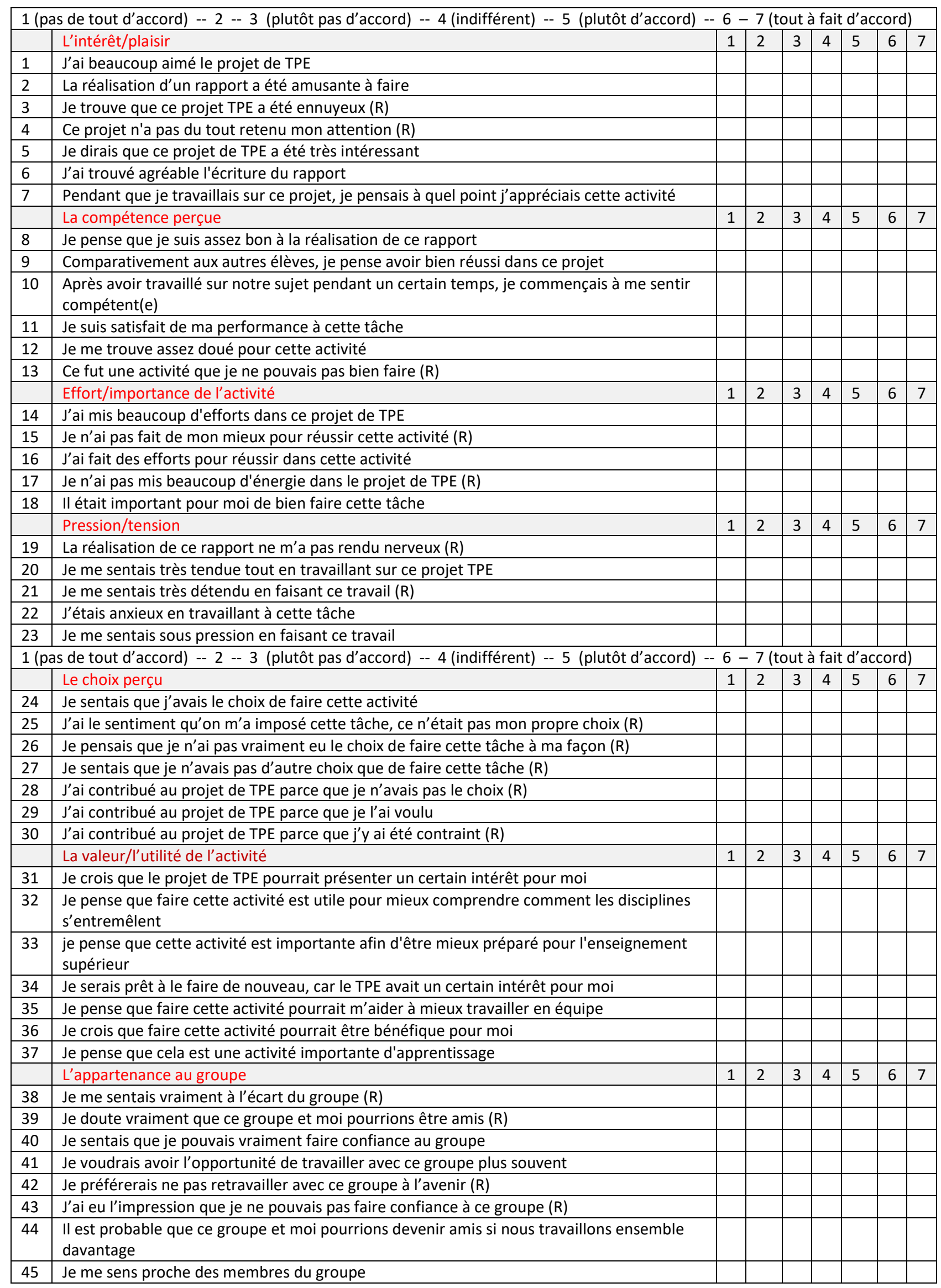




\begin{tabular}{|l|l|l|l|l|l|l|l|l|}
\hline $\begin{array}{l}1 \text { (pas de tout d'accord) -- } 2 \text {-- 3 (plutôt pas d'accord) -- 4 (indifférent) -- 5 (plutôt d'accord) -- } 6-7 \text { (tout à fait } \\
\text { d'accord) }\end{array}$ & 1 & 2 & 3 & 4 & 5 & 6 & 7 & score \\
\hline L'intérêt/plaisir & & & & $x$ & & & 5 \\
\hline J'ai beaucoup aimé le projet de TPE & & & $x$ & & & & 4 \\
\hline La réalisation d'un rapport a été amusante à faire & & $x$ & & & & & 5 \\
\hline Je trouve que ce projet TPE a été ennuyeux (R) & & $x$ & & & & & 6 \\
\hline Ce projet n'a pas du tout retenu mon attention (R) & & & & $x$ & & & 5 \\
\hline Je dirais que ce projet de TPE a été très intéressant & & & $x$ & & & & 4 \\
\hline J'ai trouvé agréable l'écriture du rapport & & & & & $x$ & 6 \\
\hline Pendant que je travaillais sur ce projet, je pensais à quel point j'appréciais cette activité & & & 6 \\
\hline \multicolumn{2}{|l|}{ Mean value of score } \\
\hline
\end{tabular}

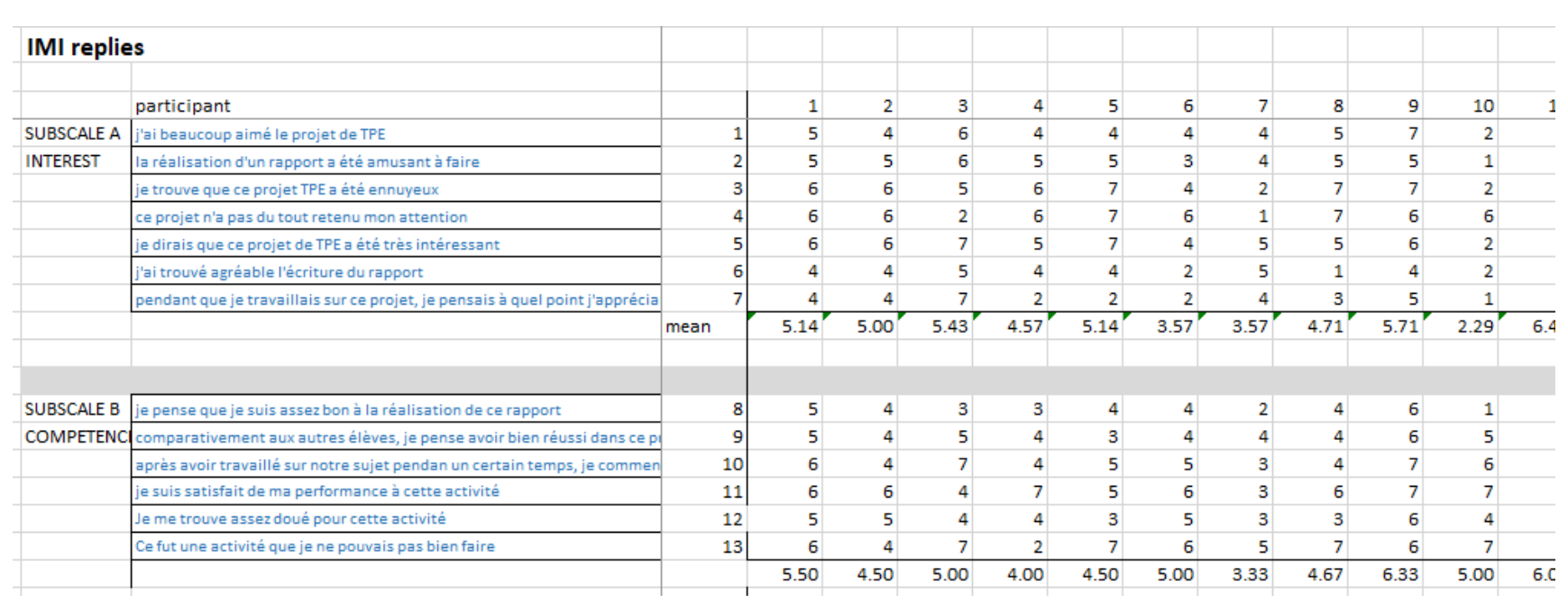

Below the original English questions of IMI.

\begin{tabular}{|l|}
\hline Interest/enjoyment \\
\hline I enjoyed doing this activity very much \\
\hline This activity was fun to do. \\
\hline I thought this was a boring activity. \\
\hline This activity did not hold my attention at all. \\
\hline I would describe this activity as very interesting. \\
\hline I thought this activity was quite enjoyable. \\
\hline I found the task very interesting \\
\hline While I was doing this activity, I was thinking about how much I enjoyed it \\
\hline Perceived Competence \\
\hline I think I am pretty good at this task \\
\hline I think I did pretty well at this activity, compared to other students. \\
\hline After working at this activity for a while, I felt pretty competent. \\
\hline I am satisfied with my performance at this task. \\
\hline I was pretty skilled at this activity. \\
\hline This was an activity that I couldn't do very well. \\
\hline Effort/Importance \\
\hline I put a lot of effort into this. \\
\hline I didn't try very hard to do well at this activity \\
\hline I tried very hard on this activity \\
\hline It was important to me to do well at this task \\
\hline I didn't put much energy into this \\
\hline Pressure/tension \\
\hline I did not feel nervous at all while doing this. \\
\hline I felt very tense while doing this activity \\
\hline I was very relaxed in doing these.. \\
\hline I was anxious while working on this task. \\
\hline I felt pressured while doing these.. \\
\hline Perceived choice \\
\hline I felt it was my choice to do the task. \\
\hline
\end{tabular}




\begin{tabular}{|l|}
\hline I felt like it was not my own choice to do this task. \\
\hline I felt I was doing what I wanted to do while I was working on this task \\
\hline I didn't really have a choice about doing this task. \\
\hline I felt like I had to do this job. \\
\hline I did this activity because I had no choice. \\
\hline I did this activity because I wanted to. \\
\hline I did this activity because I had to. \\
\hline value/usefulness \\
\hline I believe this activity could be of some value to me. \\
\hline I think that doing this activity is useful for .......... \\
\hline I think this is important to do because it can ......... \\
\hline I would be willing to do this again because it has some value to me. \\
\hline I think doing this activity could help me to ........... \\
\hline I believe doing this activity could be beneficial to me. \\
\hline I think this is an important learning activity. \\
\hline Relatedness (belonging to) \\
\hline I felt really distant to this person \\
\hline I really doubt that this person and I would ever be friends \\
\hline I felt like I could really trust this person. \\
\hline I would like a chance to interact with this person more often. \\
\hline I would really prefer not to interact with this person in the future \\
\hline I do not feel like I could really trust this person \\
\hline It is likely that this person and I could become friends if we interacted a lot \\
\hline I feel close to this person \\
\hline
\end{tabular}


Table S3. Average Semester Grades of All Classes and All Years

\begin{tabular}{|c|c|c|c|c|c|c|c|c|c|}
\hline & \multicolumn{3}{|c|}{ School 1 (2016-2018) } & \multicolumn{3}{c|}{ School (2016-2018) } & \multicolumn{3}{c|}{ School 3 (2017-2018) } \\
\hline & $n$ & $M$ & $S D$ & $n$ & $M$ & $S D$ & $n$ & $M$ & $S D$ \\
\hline $\begin{array}{c}\text { Semester } \\
\text { grade }\end{array}$ & 95 & 14.09 & 1.74 & 103 & 13.09 & 1.46 & 57 & 12.50 & 1.79 \\
\hline
\end{tabular}

